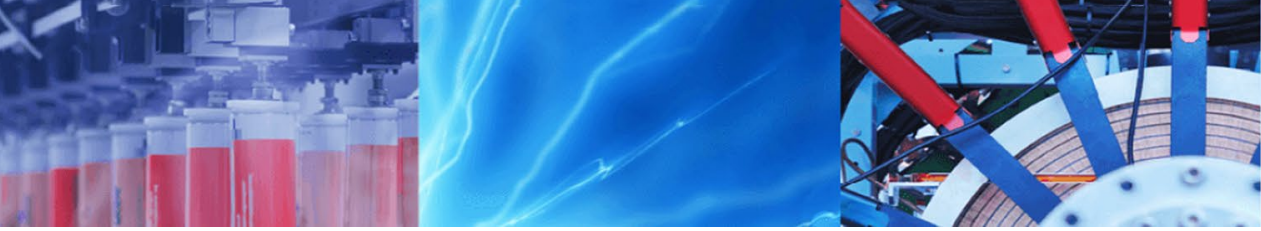

Research Article

\title{
Corporate digital responsibility (CDR) in construction engineering - ethical guidelines for the application of digital transformation and artificial intelligence (Al) in user practice
}

\author{
Bianca Weber-Lewerenz ${ }^{1}$ (D)
}

Received: 24 January 2021 / Accepted: 17 August 2021

Published online: 09 September 2021

(c) The Author(s) $2021 \quad$ OPEN

\begin{abstract}
Digitization is developing fast and has become a powerful tool for digital planning, construction and operations, for instance digital twins. Now is the right time for constructive approaches and to apply ethics-by-design in order to develop and implement a safe and efficient artificial intelligence (Al) application. So far, no study has addressed the key research question: Where can corporate digital responsibility (CDR) be allocated, and how shall an adequate ethical framework be designed to support digital innovations in order to make full use of the potentials of digitization and Al? Therefore, the research on how best practices meet their corporate responsibility in the digital transformation process and the requirements of the EU for trustworthy Al and its human-friendly use is essential. Its transformation bears a high potential for companies, is critical for success and thus, requires responsible handling. This study generates data by conducting case studies and interviewing experts as part of the qualitative method to win profound insights into applied practice. It provides an assessment of demands stated in the Sustainable Development Goals by the United Nations (SDGs), White Papers on Al by international institutions, European Commission and German Government requesting the consideration and protection of values and fundamental rights, the careful demarcation between machine (artificial) and human intelligence and the careful use of such technologies. The study discusses digitization and the impacts of Al in construction engineering from an ethical perspective. This research critically evaluates opportunities and risks concerning CDR in construction industry. To the author's knowledge, no study has set out to investigate how CDR in construction could be conceptualized, especially in relation to digitization and Al, to mitigate digital transformation both in large, mediumand small-sized companies. This study applies a holistic, interdisciplinary, inclusive approach to provide guidelines for orientation and examine benefits as well as risks of Al. Furthermore, the goal is to define ethical principles which are key for success, resource-cost-time efficiency and sustainability using digital technologies and Al in construction engineering to enhance digital transformation. This study concludes that innovative corporate organizations starting new business models are more likely to succeed than those dominated by a more conservative, traditional attitude.
\end{abstract}

\section{Article Highlights}

- Highlights the role model function of construction engineering in human-led and value-based Al for other sectors, creates awareness of the potential of digital transformation and offers constructive solutions to shape this process for the benefit of companies and society.

- Fill in the construction engineering niche in the ongoing interdisciplinary debate "Ethics in $\mathrm{Al}$ " and engage nationally and internationally recognized institutes as supporters and mentors.

Bianca Weber-Lewerenz, bianca.christina@gmx.de, http://www.researchgate.net/profile/Bianca-Weber-Lewerenz| ${ }^{1}$ Bianca WeberLewerenz Engineering, Engineering and Applied Sciences, Aichtal, Germany.

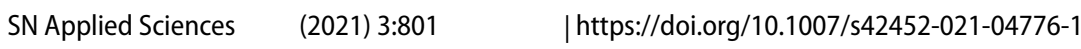


- Identify CDR with ethical principles as the key driver for success, resources-cost-time efficiency and sustainability using digital technologies and $\mathrm{Al}$ in construction engineering.

Keywords Construction engineering $\cdot$ Digitization $\cdot$ Digital transformation $\cdot$ Al $\cdot$ Ethics $\cdot$ CDR

\section{Introduction}

When science and technology, such as Al, meet human application, ethical moral issues arise. This debate is not new. Experts in Medicine, Biomedicine, Healthcare, Automotive, Ethics, Theology and Philosophy have long been analysing and critically evaluating the ethical aspects of technology's impact on human beings and society. The positive result of the inclusion of multidisciplinary aspects and revealing key factors for success in business show that such an approach in construction both supports the sustainability development goals (SDG), to develop trustworthy $\mathrm{Al}$ and uses the potentials of $\mathrm{Al}$ in a sensible and safe manner. These results are beneficial for the introduction of ethical Al debates in construction as we already know them from other sciences. Technical ethics, used as basis for ethical reflections in technical sciences, is part of ethics and, as a science, part of philosophy. It has a high practical application value because technical decision-making processes are about evaluating and weighing up advantages, disadvantages, opportunities and harm, as well as influences on the common good. In order to get closer to the design of possibilities of a successful, sustainable digital transformation in the construction industry concrete steps must be taken towards a more efficient, economic project life cycle with safe use of innovative digital technologies. Therefore, this study critically illuminates and points out both how Al may support sustainable activities and how risks lead to the need for responsible digital innovation guided by ethical principles. Digital transformation and digitization are based on Al. Al makes software intelligent and is based on data-the more, the better. Algorithms evaluate this data and recognize patterns and features. Al is the so-called umbrella term for applications in which machines provide human-like intelligence such as learning, judging and problem solving. Developing, applying and maintaining such data-driven technologies-as described in Sect. 2 and within the Case Studies requires orientation in order to be able to assume related digital responsibilities.

The core of this study lies in specifying the framework of $\mathrm{CDR}$, defining various responsibilities that corporate units need to take to carefully develop, apply and adjust technologies in the field of Al and recognize its related impact factors. These factors are analyzed and illuminated from different angles with the help of expert interviews from a wide variety of specialist disciplines and areas of responsibility. By carefully selecting the underlying data collection and methodology, various key elements could be identified. This rapidly evolving topic cannot develop its full informative value without extensive qualitative research, set of surveys and insights into the issues of ethical $\mathrm{Al}$ in the German construction industry.

Taking into account its often traditional, conservative attitude, the construction branch in particular is encouraged to act with more courage and increase the will for more innovation as it plays a significant role: nothing is shaped more by human hands than the individual manufacturing process of each individual building, in the close and reliable cooperation of a comprehensive network of construction project actors. The construction industry clearly stands out from other industries due to its individual, unique and highly demanding manufacturing process, but also due to its small-scale, fragmented industry. Therefore, new opportunities and innumerable potential fields of application for Al do exist. In addition, civil engineers have a particularly high level of responsibility in the design of living and working spaces, cities and infrastructure, in making full use of supportive technologies for the efficient, sustainable work and ethical decision-making processes. Humanity shall develop and design $\mathrm{Al}$, adapt it to new developments, control it, define fields of application and use it sensibly. Human beings are required to make use of the potential, break new ground that the technologies offer-all geared towards the common good.

The study follows an "embedded ethics approach" in the development of Al. Ethics is a sub-discipline of philosophy. It is by definition the reflection theory of morality. Even from this abbreviated definition, the question arises to what extent it makes sense to address morals to the practical questions of technology. The study clarifies the relationship between the two disciplines and adapting ethical reflection for technical decision-making to enable a safe and successful human-machine interaction. "Ethics by design" includes the ethical aspects from the very beginning: moral questions, aspects of value, search for meaningful application. Ethics is an integral part of $\mathrm{Al}$ development, since $\mathrm{Al}$ is developed, designed and used by humans. Al technologies are supposed to assist and ease human work. In Germany, this form of ethics in engineering is referred to as "Technical Ethics" following the scientific theory of technology assessment. Like Socrates, 
Greek philosopher and founder of Ethics, and the philosophical current dealing with the main question of how a person should live in order to lead a good life, this research study poses a fundamental ethical research question: How can innovative digital technology and Al be developed to ensure safe, efficient and sustainable human work and which ethical framework offers guidance and orientation?

Such a holistic research goes beyond dominant financial focus; it aims to create societal and economic benefits at its core and may encourage other branches to recognize the benefits of ethical principles of digital transformation for a strong corporate culture. The study derives this as a foundation and builds on it. Furthermore, humans must be placed in the centre of all technological developments that is a human-centred engineering. At the same time, they should be familiar with the possibilities of technology and set up an ethical framework, supporting the CDR and coping with the challenges of Al.

As this field of research fills in a new scientific niche with almost no treatment in the scholarly literature and is just beginning to be addressed by different industry and government organizations, the study itself is based on an extensive set of surveys and expert interviews. It uses the combination of insightful interviews and the survey data to develop a deeper knowledge of the issues of ethical implications in $\mathrm{Al}$, specifically in the German construction industry. Both theoretical background and comparison of recent research on the general ethical issues and connections of human-machine interactions, and the risks occurring with data-driven technologies add value to applied sciences and just emerging scholarship in this area. Among the ways of operationalizing responsible, morally reasonable handling of emerging technologies in corporate environments, the results and discussion section identifies the benefits of Al and delivers answers onto requests made by high level social and economic and political institutions for trustful, transparent Al and fulfil societal, economic and environmental responsibilities. The ongoing societal and interdisciplinary debate in media, conferences and publications is one of the key elements of CDR empowering human-friendly digital innovation.

\subsection{Theoretical background}

The evolution of Technical Ethics provides the understanding for the herein applied method, significance of selected Case studies for this study, the most recent state-of-the-art and the need of ethical frameworks for Al in construction. This new field of research extends over ethical, social, and economic impacts of digitization and Al on human, societal and technological development. Based on theories of Technical Ethics, assessment of consequences of technologies, and the critical theory of reflection in applied Technical Ethics support this design of research, lay the foundation for the critical evaluation of ethical impacts of emerging technologies leading to a new framework of technical development and application. Thus, such a practice-oriented solution, deriving from this theoretical background research, sets the foundation for corporate learning culture-in the sense of the common good and to achieve and maintain sustainable development goals [1, 2].

The term ' $\mathrm{Al}^{\prime}$ was coined by John McCarthy, in 1955. In 1975, the Asilomar Conference set a milestone by scientists and engineers' announcement of their obligation to assume responsibility. The philosophical discourse on moral and ethical questions of technology had its breakthrough with Hans Jonas' Principle Responsibility in 1979. In the 1990s, technology was considered value-neutral. Moral and ethical problems in development, design and handling of technology were reflected by Grunwald in 2013. Since the 1980s, the literature on technical ethics has increased in two areas: engineering ethics related to professional ethics and ethical questions about the newly developed technologies. With increasing technological progress and complex human decision-making processes technology ethics emerged by offering orientation to normative fears. Scientific research on human-friendly AI for the common good took off, especially in philosophy, theology, law, social and economic sciences, leading to the term 'Ethics in technology'. Grunwald [3] is a leading researcher in this field. As a result of researching trustworthy handling of $\mathrm{Al}$, industry and corporate Codes of Ethics have been developed, not least to counter the legal pressure due to allegations of discrimination. With increasing digital and $\mathrm{Al}$ technologies, research in these fields followed by humanoperated technology and the evaluation of the ethical use of technology to meet sustainability goals. The finding that trust in this new technology and understanding its function can only be created through education, awarenessraising and transparency, led to terms such as "Explainable Al". The Institute of Electrical and Electronic Engineers (IEEE) developed the first ethical standard for technology development. The construction discipline with research in digitization, $\mathrm{Al}$ and the field of ethical aspects becomes more and more visible on the German Al landscape (Fig. 1).

While the study of ethics has a history dating back to Aristotle in the fourth century BC [4], including philosophical research by Immanuel Kant [5], it remains a salient area of study, and its relevance for the area of $\mathrm{Al}$ is illustrated by publications by the Roman Catholic Church [6], the UN [7], European Commission [8] and Data Ethics Commission of the German Federal Government [9] among others. When dealing with digitization and Al the General European Data Protection Regulation 2016 prioritized the protection of 
personality, data and privacy. In the US, the White House Office of Science and Technology Policy responded with a report on how to deal with $\mathrm{Al}$ technologies responsibly within the rapid global digital transformation [10]. Scientific literature reflects the broad discourse on humancentred AI design and CDR with titles such as "Possibility of the good-Ethics in the twenty-first century" [11],"Digital ethics-A value system for the twenty-first century" [12], "Digital humanism-An ethics for the age of the artificial Intelligence" [13], "Al—What it can do and what awaits us" [14], "An algorithm has no tact. Where artificial intelligence is wrong, why it affects us and what we can do about it." [15]. Still, related literature in construction is missing and thus, provides the argument to fill in the gap with this study.

\section{Methodology}

The research gap was addressed through Case studies from business practice as part of the qualitative, structured research methodology. Experiences and observations on multiple real-life applications, as part of empirical social research for systematic data generation, provided adequate resources. The reason for choosing this method is that the field of research is a marginal area; the topic is still new, there is only literature in other sciences. Intensive expert interviews conducted by the author as part of this study's qualitative inquiry and research design offer the best method for performing research in applied sciences for gaining knowledge and deep insights into the status and use of technologies, ethical attitudes, opinions, motivations to act, needs, tendencies, critical reflections, social problems as well as recommendations for constructive solutions [16]. The Case studies are extremely illuminating in that most of the shared experiences and background knowledge explain the complexity of impacts and influencing factors that are heavily dependent on one another or are mutually dependent. This method was found as to best allocate CDR and provide approaches for its adequate ethical framework design to support digital innovation in order to make full use of the potential of digitization and $\mathrm{Al}$ in the construction industry. The development of interview guidelines on the research-relevant criteria, subject areas, indicators, with open and closed questions served as an instrument for data collection. This serves to map the complex practice of everyday values and empirical values: the identification of additional influencing factors, gaining systematic knowledge of entrepreneurial thinking, handling and proceeding, recording, processing and documentation of data, deriving strategies, localizing responsibilities. Based on surveys being conducted on a yearly basis - the first was performed between November 2019 and December 2020 applying partially standardized scientific questionnaires and field notes on ongoing interactions in various types - the following methods are essentially used for data collection for this interdisciplinary, holistic approach: personal and written interviews by personal meetings or telephone conversations, observation (in person in the research field or by video), written documents (media reports and files), email communication and round-table discussions with respondents. Expert surveys were carried out with the aim of obtaining profound, detailed data at all levels of working fields and responsibilities. German and international construction engineering associations, Chambers of construction trade associations, Departments for digital transformation in German Ministries, research centres, educational and academic institutions and Ethics and Al Institutes participated in that survey. Such frequently conducted surveysannually or biennially_allow for the regular monitoring, analysis and evaluation of a more accurately generated set of data, along with the relatively new development and applications of these technologies. The present study is based on the first round of interviews receiving 90 per cent of survey responses. For this survey, the author selected 50 leading experts from research, transfer institutions and associations with focus on the research area. Al in large companies and medium-sized companies is still in its early implementation phase, but understanding and awareness are increasing. In an early market phase, scientists are usually more familiar with the opportunities and challenges of the new applications than representatives from practice-due to a lack of pool of users. Also, the experts being interviewed mainly come from the transfer area at the interface between science and implementation in practice. For this reason, the respondents are familiar with the business challenges. As Al and digitization are in their early stages, the interviewees, adopting these methods and tools, belong to a younger generation- -30 to 45 years old-and are academically trained in new innovative fields of engineering and IT. Around $20 \mathrm{Al}$ and ethics experts are representatives from Fraunhofer and Max Planck Institutes, Al and Ethics Research Associations in Baden-Württemberg such as the Cyber Valley in Tubingen-Stuttgart, Al research centres at universities, country-specific building information modelling (BIM) clusters and institutes for business ethics and academic representatives of Civil Engineering. Table 1 visualizes the extract of the survey's questions.

Around 30 representatives from politics and business took part in the survey, including steering groups for sustainability and digitization, global corporations, companies playing a pioneering role implementing digital 


\section{Map of selected location: Al in Construction in Germany}

(Source: Research by Bianca Weber-Lewerenz in the field of "Corporate Digital Responsibility (CDR) in Construction Engineering - Ethical Principles for Digitization and Artificial Intelligence (Al)")

Companies

\begin{tabular}{|l|}
\hline HOCHTIEF, Essen \\
\hline STRABAG, Köln \\
\hline $\begin{array}{l}\text { Wayss \& Freytag Ingenieurbau AG, } \\
\text { Frankfurt a. M. }\end{array}$ \\
\hline
\end{tabular}

APLEONA Gruppe, Frankfurt a. M.

\begin{tabular}{|c|}
\hline $\begin{array}{l}\text { M\&M Networking-Ing, Mainz (Start } \\
\text { Up) }\end{array}$ \\
\hline Vollack Group, Karlsruhe \\
\hline AMAI GmbH, Karlsruhe (Start Up) \\
\hline $\begin{array}{l}\text { PERI Vertrieb Deutschland GmbH \& } \\
\text { Co. KG Scaffolding Formwork } \\
\text { Engineering, Weißenhorn }\end{array}$ \\
\hline Nemetschek SE, Munich \\
\hline
\end{tabular}

\section{Ethics lon A ln Construction}

Bianca Weber-Lewerenz Engineering ${ }^{(1)}$, Stuttgart (Aichtal)

\section{Research}

\begin{tabular}{l}
\hline Bergische University \\
Wuppertal \\
\hline
\end{tabular}

ICoM, Institute for Construction Management and Digital

Construction, Leibniz University, Hannover

\begin{tabular}{|c|c|c|c|}
\hline TU Darmstadt & \multicolumn{2}{|c|}{ TU Kaiserslautern } & TU Munich \\
\hline \multicolumn{4}{|c|}{ Karlsruhe Institute of Technologies (KIT), Karlsruhe } \\
\hline \multicolumn{2}{|c|}{$\begin{array}{l}\text { Fraunhofer Institute IAO, } \\
\text { Stuttgart }\end{array}$} & \multicolumn{2}{|c|}{$\begin{array}{l}\text { Cyber Valley Stuttgart- } \\
\text { Tübingen }\end{array}$} \\
\hline \multicolumn{4}{|l|}{ Prolects } \\
\hline \multicolumn{2}{|c|}{$\begin{array}{l}\text { Al Innovation park Baden- } \\
\text { Württemberg (in planning) }\end{array}$} & \multicolumn{2}{|c|}{$\begin{array}{l}\text { ESKIMO Project: Al onsite } \\
\text { (ongoing) }\end{array}$} \\
\hline
\end{tabular}

Inldatives, Assoclations

BIM Germany, Berlin Center for Digitization in Construction

BuildingSMART Germany

Al-Plattform for Construction: Research Network "Smart Design and Construction through Artificial Intelligence" (SDaC), Goldbeck, Bielefeld, and KIT, Karlsruhe

Association of German Engineers VDI Verein dt. Ingenieure e.V., Düsseldorf

Association for value management EMB Wertemanagement Bau e.V., Munich

Befive corporate partnership,

Munich

Initiatives „Handwerk meets BIM“, "Handwerk\&KI"

\section{Asoodiations, Unilons}

Main association of the German construction industry e. V., Berlin

Bavarian Construction Industry Association e.V., Munich

igbau ConstructionAgricultural-Environment Industrial Union, Frankfurt

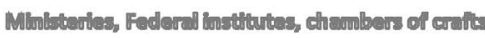

Federal Institute for Building, Urban and Spatial Research (BBSR) in the Federal Office for Building and Regional Planning (BBR), Bonn

Ministry of Economy Baden -Württemberg, Stuttgart

Chamber of Craft HWK Handwerkskammer, Stuttgart

Map Al in Construction in Germany (extract) Source: Bianca Weber-Lewerenz Status: January 2021

(1) First time research on the ethical principles in Al in Construction (start: 2019, ongoing)

Fig. 1 Map of selected location: Al in construction in Germany. Source: Bianca Weber-Lewerenz 
technologies which are considered as best practices, and small and medium-sized enterprises (SME).

Selected aspects of the results of the survey were then subjected to an in-depth analysis with the help of expert interviews (Table 2). Additionally, the study made full use of collecting data by national and international research literature, books and journals, exchanges between experts shared by international virtual panel discussions and forums, cyber forums, $\mathrm{Al}$ and Ethics roadshows, virtual summits, presentations, interviews and speaker series, group discussions and observations on media reports.

Each interview conversation was planned and systematically analysed afterwards. Typing and interpretation were used for the evaluation process. In the qualitative content analysis, the interviews were interpreted and evaluated according to a rule based on a question [17]. On this basis, a summary content analysis can be carried out. Here, the examined material is reduced to a manageable short text. Only the essential content is retained. In this way, a manageable body of all the material can be created. The summary content analysis is particularly useful in this research, as one is interested in the content level of the material. With the help of case and group comparisons, similarities and differences between individual respondents could be worked out, as well as final generalizations could be derived [18].

A strong point of the study is the cooperation with Fraunhofer IAO Institute Stuttgart in the frame of presenting new findings in a common study on "Al in Construction Industry" [19]. Secondly, a global player company requested new findings to be introduced into the corporate ethical framework, Al customized. Thirdly, the research results are also made available to an association that certifies and audits ethics management in construction companies, including potential corporate adjustments that this study recommends for the meaningful use and safe handling of digitization and Al.

The key findings and deriving recommendations are shared with the Task Force on Digital Transformation at the T20 Conference in preparation of the decision papers for the G20 Summit in October 2021.

It should be emphasized that this is an expert survey. Therefore, there is no claim to representativeness. Furthermore, this study is about an in-depth assessment by technical experts.

\section{Results and discussion}

\subsection{Results}

The construction industry is challenged by both corporate social responsibility (CSR) and CDR in an era in which Al is expanding. Thus, technologies require corporate responsible handling by reflecting their own social responsibilities towards human beings and society. CDR was found a key factor for enabling successful digital transformation in companies and to fulfil their responsibilities. As a result of the high demand for both technological development and value-based decision making, CDR has come into focus within the construction industry as a feasible holistic approach to enable the implementation of human-led digitization and Al. Employing Case studies, the study reviews status quo, new technologies, interdisciplinary interfaces, current research, design of practical implementation and the ethical and legal framework. One of the evaluation results of the interview surveys is the strong need for guidelines, standards and binding rules, also in legislation. Further, the educational landscape has to be adjusted in such a way that the next generation of engineers will not only have expanded skills in digitization and $\mathrm{Al}$, but also possess the necessary ethical and multidisciplinary competencies.

The construction industry has proven to be a good example for demonstrating existing gatekeepers, barriers, partial prejudices, negative attitudes and a lack of both digital and Al education and encouragement of constructive approaches to overcome and strengthen a sustainable digital age. The strengthening of inclusion and diversity do not only derive from an ethical responsibility but also from the principle of the common good [20] and the expansion of the value chain as to mobilize resources to achieve an 'ecosystem of excellence' [21].

Despite strong order books, construction and engineering companies face sustained cost pressures and the lack of a skilled workforce. New digital technologies and Al help to realize new operational efficiencies, new business models, increase education for newly required qualifications and offer new workplace solutions and job opportunities. New digital technologies include digital twin, 7D simulation, 3D modelling by building interior scan and exterior drone scan, visualization and building accessibility. Methods of $\mathrm{Al}$ are based on machine learning, deep learning, predictive analysis and technologies as to enable applications such as Al-based data and project management, Al-based process performance, Al-based technical building automation and automation of engineering tasks, parametric design, generative design by programmed algorithms, visual image recognition, semi-automatic component recognition.

The construction industry plays a vital role in national economies: it had a significant positive impact to the US economy by added more than $\$ 900$ billion in the first quarter of 2020, which is the highest levels since the 2008 recession [22]. Construction is considered a major driver 
Table 1 Extract of the survey questions. Source: BiancaWeber-Lewerenz

$1 \quad$ What is your opinion on the status quo of digitization and artificial intelligence (Al) in the construction industry?

2 Why does only a minority of construction companies use digital method such as BIM?

3 Do you use? If yes, what are your experiences? If no, what are the problems and limitations?

$4 \quad$ Where do you see the potential of ethical framework and standards for the use of digital technologies and Al in construction?

$5 \quad$ Compared to other branches, construction industry plays a special role in modern digitalization methods. What is it about?

$6 \quad$ Where do you identify and allocate the use of digitization and artificial intelligence (Al) in the construction industry?

7 Your company increasingly uses digital methods and AI. Which ethical standards and framework are necessary for the responsible handling in construction companies, especially with data, from your point of view?

$8 \quad$ Why do you think ethics should be part of academic engineering training?

9 What's your estimate of the need for digitization and Al in construction? And what are the most important skills of engineers-professional and personal-to successfully face the challenges of digital transformation?

10 What's your estimate of the willingness of construction companies to integrate digitization?

11 What limits and risks does a company experience when implementing digitization and what opportunities arise? (e.g. in the field of technology, people and specialists, company structure, ethics, mission statement, law, politics, etc.)

of the German economy and also the sector with the highest $\mathrm{CO}^{2}$ emissions, specifically in cement production. As a result, the construction industry and its associated companies bear significant responsibilities for the environment and climate. The challenges can be met by data-driven technologies that decrease the use of resources, ease efficient project life cycle, ease human work and make it safer, and support all sustainable activities involved such as long-term corporate digital business models and the education of qualified personnel. The current performance of construction projects struggles to keep within budget, time and to maintain high-quality standards, but especially lacks efficiency in all processes involved. Digital technologies and Al could enhance significantly the efficiency at all levels, but first needed corporate responsibilities have to be mastered. The increasing complexity of processes and the occurring risks of digital transformation on both human, technologies and human-machine interaction itself lead to a need for responsible innovation, orientation, sensible and safe development and an overall CDR culture in the construction industry. The study identified the design of CDR for the digital transformation process as a key solution.

Although CDR can help enlarge value chains, save longterm costs, and achieve sustainable development goals, it is not yet broadly used and thus its full potential has yet to be reached. Stakeholder concerns, missing transparency, environmental restrictions are among the obstacles that hinder widespread adoption of CDR [23]. In fact, to achieve sustainable innovation, including the use of digital methods and $\mathrm{Al}$, it has been suggested that ethical decision processes should be institutionalized in corporate culture on a global basis [24]. Instead of examining the question "Is the new airport in Berlin a curse or a blessing?" the study is devoted to "CDR in the construction industry and ethical principles" in order to urgently raise awareness of methods and potential fields of applications of digitization and Al. The study identified moral and ethical principles as key for orientation in both researching and applying these technologies, and as essential factors for successful sustainable digital transformation in complex decisionmaking environments.

The study identifies approaches to develop, control and apply technology and science in an ethically and morally justifiable manner. The evaluation of the respondent's results shows that $\mathrm{Al}$ has potentials in many fields such as easing human work, data accessibility, increasing project time and cost planning efficiency, quality, safety and risk management, protecting natural resources and climate a well as enabling new competitive, innovative business models. At the same time, the study's approaches by the construction engineering discipline answer international, national and UN white papers' requests for responsible, safe and sustainable human-technical interaction in the frame of these vibrant and quickly growing $\mathrm{Al}$ technologies. Thus, it contributes on an economic, social and ecological level. Germany has an important role model function for other countries to lead into the new century of technology.

The collaboration with Fraunhofer Institute IAO for including this study's ethical aspects in the study on Al in construction, commissioned by Cyber Valley in 2020, highlights the pioneering role and urgent need for action in embedding ethical principles into the earliest phase of technological development and its fields of applications. This close cooperation between strong partners coming from research and applied science sends a strong signal, especially to corporations, both intensifying the awareness 


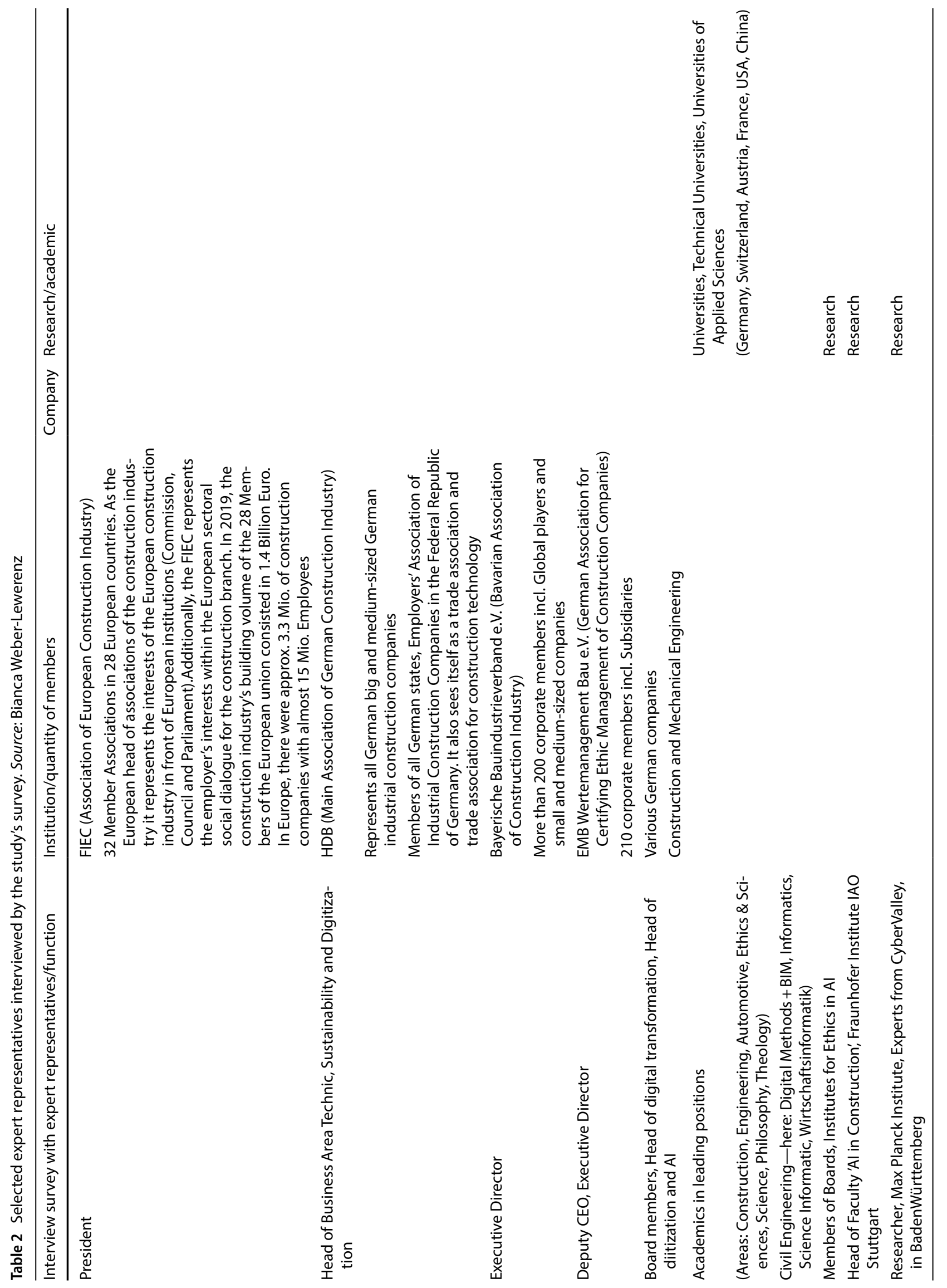

SN Applied Sciences 
of ethical fundamentals in digital transformation discussions and focussing on the significant potential of Al technologies and methods in construction industry as well as providing adequate corporate digital infrastructure.

The study's results do not only offer an added value to the scientific, multidisciplinary discussion on 'Ethics in $\mathrm{Al}^{\prime}$ and complement current research debate on the potentials in construction, but also enhance the efficiency of the project life cycle and sustainable digital transformation led by ethical principles and a human-led Al. The study led to elevate the construction industry into the most recent research study called AI ULTRA, promoted by the German Federal Ministry of Labour and Social Affairs, aiming for guidelines for action and an evaluation toolkit. Organizations can fully exploit the potential of Al technologies, face this complex human and technical transformation process and use Al-based technologies sensibly and safely.

Since this is a whole new scientific field of research and the topic has not been examined before, this study could not include a section that highlights a comparative analysis with previous studies.

\section{Discussion}

\subsection{CDR in general}

One of the core tasks in the digital era for decision-makers in social, political, educational and corporate environments is to identify the benefits of Al and how to operationalize it in a responsible, morally reasonable way [25, 26]. There is a consensus between all interviewed experts: it is essential to strengthen entrepreneurship ecosystems by diverse approaches. The study shares the essence in the following and adds interpretations. Emerging technologies play a fundamental and catalytic role in digital transformation. The pandemic crisis has highlighted the need, value and appreciation for empathic and humble leadership styles. The Critical Path, that this study reveals, consists also in strengthening inclusion and diversity that does not only derive from ethical responsibility, but the principle of the common good and the aim to expand the value chain. The construction industry, experiencing a continuous decrease in skilled workmanship, could benefit in various ways from an inclusive debate using women's potential to empower digital innovation and digital economy as the facts speak for themselves: a not negligible part of financially successful companies are led by women. Al subsumes numerous applications that have one common characteristic: taking over cognitive tasks that previously only could be done by humans. This is why human beings and machines move increasingly closer together. In this context, diversity represents the key to avoid gender bias, discrimination and filter bubbles in developing datadriven tech.

Furthermore, despite strong order books, construction and engineering companies face sustained cost pressures and the lack of a revised and adjusted educational landscape to produce a skilled workforce. New digital technologies and AI help to realize new operational efficiencies, new business models, increase education for newly required qualifications and offer new workplace solutions and job opportunities. The construction industry could benefit significantly by implementing the strategic decision-making processes, planning and operational phases more efficiently by both standardizing digital technologies, methods of Al and increasing corporate women leadership. In short, diversity is essential to a cutting-edge portfolio in construction to shape digital transformation holistically, successfully and sustainably. Proof of hard facts such as the increase in economic efficiency (ROI) and overall excellence in corporate digital culture-evidenced in yearly corporate reports-rationalize gender discussions. It is time to fundamentally rethink technological progress enabling new business models in construction and to keep up with digitization in a sustainable manner, by empowering digital innovation, digital economy, inclusiveness, gender parity, safe and transparent human-machine interaction. To achieve such goal, societal and ethical issues need to be identified and dealt with as rapid technical developments such as Al require control and orientation on what is harm or added value for human. Technical business transformation includes digital transformation by synchronizing and harmonizing with a profound human transformation. This transformation will cause technological, social and cultural disruption that will redesign the way we live and work. To shape this transition successfully, Ethics is perceived as an empowering way to recognize the values of a society in corporate culture and decision-making processes, empowering human growth, technological development, trust, responsibility, and consciousness.

\subsection{Diversity}

Intensified by digital change, inclusion, diversity, corporate governance, integrity, gender gaps, mandates and boards for financial and societal benefits increasingly come into focus [27]. Unfortunately, algorithms all too often have a "gender bias", a gender-related distortion effect, for example male thought patterns in the selection of job applicants leading to discrimination, as algorithm experts discuss around the globe. Scientific journals reflect the significant increase of scientific research in this specific field. They address the sources and detection of gender bias, consequences and options to mitigate and prevent. One key finding is that digital technology helps both to 
remove existing gender bias, for example in academia, and prevents inequality in researching and developing Al. Thus, it is even more important to perform targeted training of machines, algorithms, and learning systems by multi-diverse teams. Understanding such interactions and dependencies among each other, $\mathrm{Al}$ is seen as an answer on sustainability and a fair gender future; it is the approach for operationalizing the White Paper on Al of the European Commission. There are four main pillars of disruptive and transformative change our society needs to undergo due to the technological advances: educational, professional, cultural and governance.

Some of the latest emerging technologies (such as Blockchain, Al, Next Generation Computing, 5G and 6G, $3 \mathrm{D}$, loT, $A R, V R$ and $X R$ etc.) can serve as catalysts or gateways to enhance inclusion and diversity when deployed mindfully. However, they can also easily become the conduit for severe unintended consequences that worsen the gender gap. Developing state-of-the-art proactive digital ethics programmes that facilitate and accelerate the attainment of the United Nations Development Goals would be ideal for a long-term success.

\subsection{Regulation}

Ethical and moral aspects are the top priority when it comes to ensuring corporate governance, required by legislators and stock exchange regulators as a result of corruption scandals, racism, and manipulation of technology in various industries. Over the past years, stakeholders increasingly requested transparency in the yearly corporate reports. Another option considered as a corporate responsible response seemed to be to hire a Chief Ethics Officer. Often such a department covers corporate diversity, inclusion, the promotion of women in management and leadership positions. More and more companies realize the significant role of $\mathrm{HR}$, digital ethics, and corporate digital responsibility to shape a successful digital transformation. Thus, digital change speeds up the process of these previously separately working units to increasingly grow together.

Diversity and digital transformation are closely linked. It is seen that the widespread implementation of both is essential to exploit important potential for both the entrepreneurial and the common good. On the one hand, the goal is to conserve resources, the climate and the environment, to think through the construction cycle from the project idea to dismantling and recycling, on the other hand to create attractive structures that are optimally embedded in the landscape, efficiently operated, and usable for generations, supported by constantly evolving technologies, used sensibly and with awareness of values. The scientific debates in the areas of quantum computing, blockchain and digital currency, which are developing just as rapidly as $\mathrm{Al}$, have recognized that ethical issues must also be incorporated.

\subsection{Standards}

The ultimate goal is to achieve a relation of morality and technology and human-tech interaction that is healthy for human beings, taking responsibility as corporations for digital environments, the fields of using $\mathrm{Al}$, evaluating its chances and its risks, and to encourage developers and users to act responsibly. To allocate and examine opportunities and risks of human-led technologies undergoing digital transformation is seen as key responsibility in order to deal with them in a targeted manner. One of the major outcomes of this scientific study in construction, in addition to studies in other sciences on Al in general, is the finding that standards and binding rules of the ethical framework for using Al must be set on the political level and by law. The reasoning goes as follows: pure personal responsibility is no longer enough, because many companies ignore it or cultivate "Greenwashing". Furthermore, Al can be manipulated and used in a discriminatory manner. Another finding is that the educational and academic landscape has to be adjusted in such a way that the next generation of engineers not only have expanded skills in digitization and $\mathrm{Al}$, but also possess the necessary ethical and multidisciplinary competencies. In fact, to enlarge value chains, save long-term costs, and achieve sustainable development goals (SDGs), it has been suggested that ethical decision processes should be institutionalized in corporate cultures around the globe.

This study is part of a larger research project of the author, which goes beyond the dominant financial focus and aims to create societal and economic benefits for the construction industry at its core. The construction branch is envisioned to encourage other branches to recognize and fully use the potential of the ethical implementation of digital transformation within a strong corporate culture. This research is met with the utmost approval to enhance the awareness, education and application of Al. The popularity of the topic among expert groups inspired the author to found the "Excellence Initiative for sustainable human-led $\mathrm{Al}$ in Construction" in 2020. It strengthens the dynamics of such processes in order to give this industry a pioneer role. To a larger extent, the initiative symbolizes a milestone on the way to bridge the gap between technology and philosophy and practicing interdisciplinarity for a common societal goal.

Here, the construction industry is not yet visible. Digital transformation and $\mathrm{Al}$ are changing this perception. Language transfer, transparency and education are essential for gaining trust in new technologies, participating and 
shaping the digital transformation process, moving forward and fully using all potentials. Construction has just started applying first digital methods, and the first Al tools can simplify, augment and amplify human efforts. The understanding and knowledge of such technologies are still limited to a minority of people in research and development, leading to the conclusion that its opportunities, the risks and weak points of the technology need further education, communication and transparency. These new technologies offer new fields of qualifications and competencies. They create more economical and efficient handling of projects, transferring routine processes to machines, increasing protection of climate and of human and material resources and fulfilling sustainability goals. First experiences in the practical application of digitization and $\mathrm{Al}$ show how these new technologies relieve and support people, make human work safer, facilitate communication and make work processes even more secure.

\subsection{CDR and CSR in practice}

Ethical responsibility in Al has been emphasized since their application is soaring without much consideration of both positive and negative impacts on the construction industry. The importance of Ethics in Al and the lack of consideration of the construction industry's CDR is pointedly emphasized by the lack of research prior to this study. The high level of practical relevance strengthens the construction sector. The study appeals to large, medium and small companies as the interviewed experts share their experiences with these corporate backgrounds. The construction industry has a prominent position with its unique, highly demanding manufacturing process of each individual building and large networks of numerous construction project participants. All interviewees conclude that to plan, execute and operate projects more efficiently-especially on a more sustainable economic, social and ecological level-digitization and Al are indispensable to support human work, performance and processes. In terms of the precautionary principle, technology is not just a question of ability. In spite of all human freedom, the understanding of progress should lead to the design of technology that is healthier, more humane and more social for us humans. Civil engineers have a particularly high responsibility: to create working and living space of the highest quality for people and to work in a way that conserves resources. On the one hand, their goal is to protect the climate and the environment from the project idea to dismantling and recycling. On the other hand, they aim to complete building projects faster, cheaper and at high quality, to provide optimized infrastructure, optimally embedded in the landscapes, efficiently operated. In doing so, the processes are supported by constantly evolving technologies.
Construction industry is associated with multiple high risks in cost and budget, time planning and quality. These can be minimized with the help of digitization and Al. The civil engineer creates places to live, to work, places to meet, but also faces increasingly complex data environments such as project data documentation. The responsibility to use these technologies sensibly in the design, implementation and use of buildings, must be met morally and ethicallyconsciously and well beyond the technical standards and regulations. Because only by bringing together the core competencies from disciplines required for the holistic evaluation (civil engineering, interdisciplinary technology, technical ethics, digital ethics, philosophy, information technology and software) - as this study finds out-the topic of digitization and $\mathrm{Al}$ in construction can be comprehensively dealt with and firmly anchored in research and teaching.

One of the results after evaluating this study's interviews is the omnipresent interaction of key elements of CDR elaborated together with experts in the construction branch. The overview illustrates these elements which are key for helping to shape the digital transformation responsibly and with long-term effects, while being mutually dependant-visualized via a "mind map" (Fig. 2).: building up knowledge and competencies, designing all basic technical requirements, interdisciplinary cooperation.

Such an intense debate on human-tech interaction, responsibilities involved and framing ethical standards requires a clear distinction between human and artificial intelligence in order to define risks, overall potential, and areas of application. According to Al developer's statements, it remains a human key responsibility to programme, guide, control, adjust, manage and maintain data-driven tech: digital transformation has the great potential to aid both the economical and efficient building project life cycle, but technologies involve responsible handling, deployment, management and monitoring. In order to fundamentally rethink technological progress in construction and keep up with digitization in a sustainable manner, everyone involved is challenged to lead this process to success and shape it proactively with qualified human resources, an open discourse on new technical possibilities and the allocation of potential fields of application. Coping with this challenge is a top priority in construction. Nevertheless, there is a lack of recognizing fields of application and a lack of diversity. Knowledge about digital technologies and methods must first be acquired comprehensively to be able to assume digital responsibility for something that many do not yet know or cannot assess. It is a prerequisite for the greatest possible social benefit, economic prosperity and protection of our natural resources. It is time to set new sails to navigate digital times in a powerful, enriching, sustainable way. Best 
practices are evidence that disruptive changes to existing corporate digital culture are a driver of more efficient corporate and project processes, and thus, for the increase in human and financial profits. The incentive to disrupt older processes will often spring forth new systems and methods that have the potential to be leaner, more efficient, less prone to error, and more cost effective across the enterprise.

Four basic ethical principles of Al have been laid down by the EU Commission in its ethics paper-promoted by the Enquête Commission of the German Bundestag "Artificial Intelligence-Social Responsibility and Economic, Social and Ecological Potential" [28]. These are more relevant for the construction field than ever: Al should preserve human autonomy, avoid social damage, act fairly and remain explicable. This study derives the ethical framework by bridging the gap between these principles and virtues, ethics, digitization and $\mathrm{Al}$ in construction. German companies consider corporate culture, ethics, appreciation, and wellbeing of people as decisive strategic importance for corporate success. But how do we want to design this technology? What are our expectations? How should it support us? Can values be guidelines for this technology design? How do we best familiarize ourselves with the new technologies? Which fields of work do we not transfer to machine? Which problems do we see, where do we allocate and how do we solve them? Questions that are of great concern to human-technology interaction. Algorithms are part of everyday life for computer scientists. Thus, a negligible proportion of society is familiar with $\mathrm{Al}$ and speaks such expert language. Trust in this new technology can only be established and built up by having access. Therefore, the study concludes that Al needs to be explainable, awareness must be created, and people have to be sensitized. The respondents clearly distinguish between human and artificial intelligence: it is human intelligence that programmes, guides, controls, corrects, manages and maintains Al. Digitization and Al are ethical challenges, human values and morals remain the most important tool kit to integrate. They help answering questions as to whether and how these technologies and methods can be reconciled with our moral ideas, what kind of concerns are perceived, which opportunities and advantages of technology should be used from an ethical point of view in the sense of the common good.

The ethical component of Al provides orientation for action. A vivid corporate culture practiced by corporate management is beneficial both to stand out from the competitive market and rapid global change and to strengthen human values in increasing complex working environments. Algorithms make assumptions containing evaluations, but humans provide data and personal assessment. Construction has just started to examine first digital methods, applying BIM and using first Al tools, considered to be a new work-life that makes human work on construction easier. The understanding and knowledge of such technologies remain limited to a minority of people who develop or start using them. The study came to the conclusion that its opportunities, the technologies' risks and weak points need stronger communication and transparency. Ethical principles for human-led Al in construction have not yet been recognized although there is a strong need to develop and enhance a value-based $\mathrm{Al}$ consistently. One of the study's intentions was to engage the construction engineering discipline for multidisciplinary dialogue on 'Ethics in Al' and to define its own ethical framework for the benefit of its own branch. The impacts of Al on society are reason to perform this study now.

Opportunities and high potential of digitalization in construction offer approaches to adopt new methods from $\mathrm{Al}$, build on existing digital data structures, e.g. BIM, and make them more efficient. Another of the study's findings is that success and sustainability can only be achieved by recognizing opportunities, actively shaping digital change, interdisciplinary critical analysis, changing perspectives and complementing one another. One model-based working method that takes advantage of the innovations of the digital age is BIM. This method enables up to 7D-modelling of buildings, building equipment of all integrated specialist disciplines, and construction process planning. Data can be linked over the entire lifespan of the building, be added and exchanged continuously by all parties involved including building owner, planner, architect, engineer and technical building automation (technical building equipment and automatization: electrics, plumbing, ventilation, heating, light). This digital method can be assigned to tools of $\mathrm{Al}$, in short: $\mathrm{Al}$ may enlarge existing digital structures of BIM and a more efficiently functioning simulation modelling. Facilitating forecasting and corporate strategy based on simulation models, it provides decision-making sources for the planning and construction process. By integrating all digital devices, data can be secured and interfaces can be merged within multidisciplinary environments.

The question is why do only $5 \%$ of German construction companies use BIM [29] even though BIM is required by law since 2020 for the tendering and execution of public works contracts [30]? Representatives of the German construction industry share and help identifying some of the reasons and possible solutions in expert interviews. All project participants' responsibilities, in each individual project phase of the construction project life cycle, lay the foundations for the corporate digital infrastructure and its application: from the company management over executors to the building users and operators. By this study's evaluation, the problem sources for the low number of users of BIM and their hesitations could be localized in 


\section{mind map "The interrelationship among the key elements of CDR"}

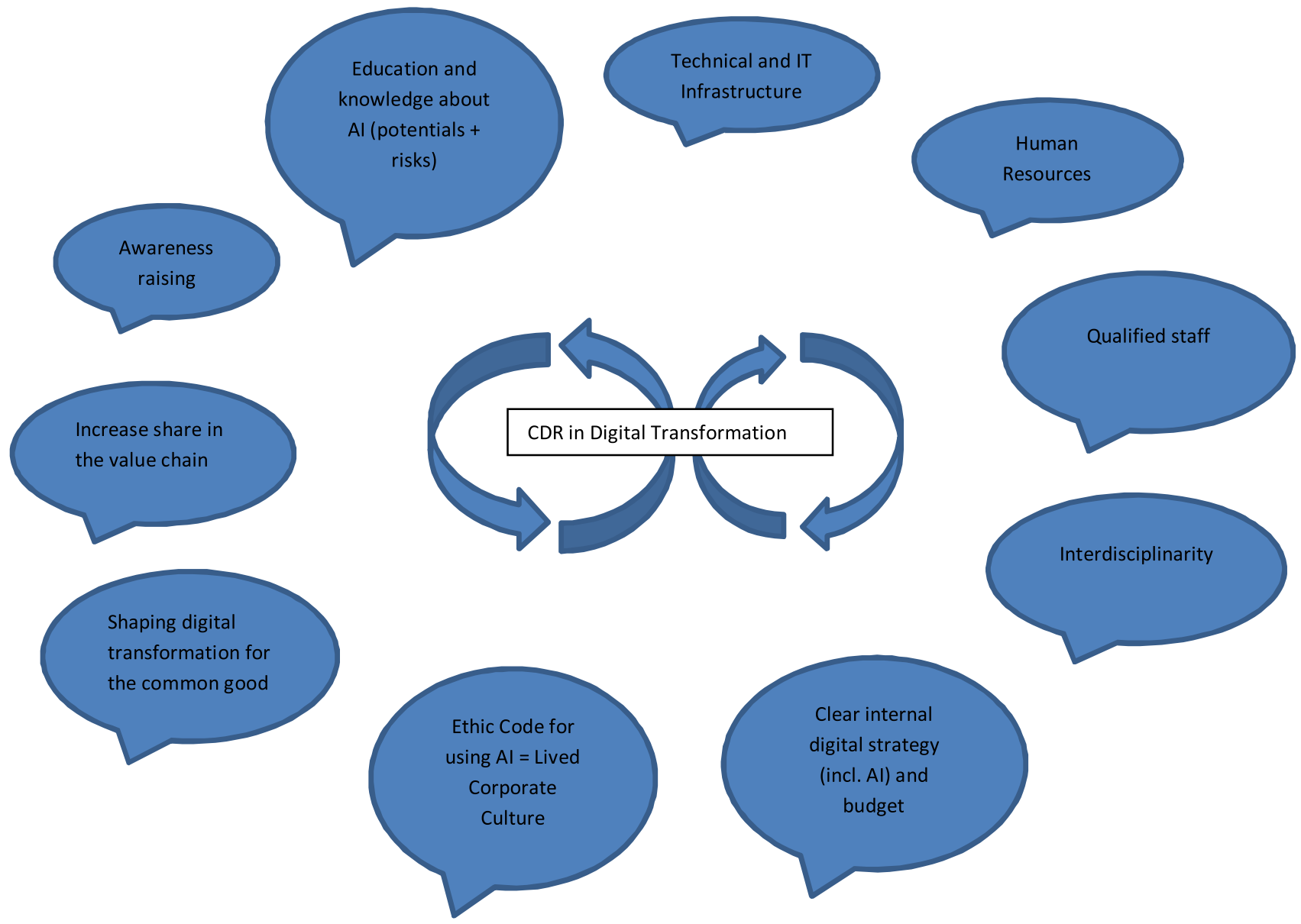

Fig. 2 Mind Map "The interrelationship among the key elements of CDR". Source: Bianca Weber-Lewerenz

unresolved questions of contract law (ownership of the building model data etc.), missing definitions of interfaces, ignorance of the benefits and advantages, as well as uncertainty in the application, open liability and copyright issues. Further reasons are unanswered questions about the coordination management of BIM, cost aspects of new BIM software, training, and IT infrastructure, questions about the compatibility of BIM (technology, software, data security, data protection), non-existent legal regulations since BIM application of public and private clients and contractors has not yet been legally required. BIM may serve as technical requirement for new digital technologies such as Al. To comply responsibly with both shaping the design of the digital transformation process and sustainable, resource and climate-friendly construction, active participation is required at all levels. The study builds on these initial findings to draw new conclusions as to how a successful digital transformation can be complemented by ethical guidelines. To cope with these two significant requirements, in addition to CSR, considerable amount of responsibility is allocated with corporate management:

- utilizing digitization,

- acquiring comprehensive knowledge of fields of application,

- benefits,

- forecasting options and risk areas,

- enabling access to digital technologies,

- offering training,

- participating in the technical progress, recognizing human values,

- taking measures to protect them,

- protecting data-including company data, personal data, and protection against data misuse,

- using Al for routine processes that lighten the workload and designing efficient work processes such as Lean Construction [31]. 
The responsibility of the project participants among others as the study examined is to gather regular lessons learned to supply data, to avoid data loss, and to share knowledge, to use historical and new project data for comparative analysis. Fast data access also means using economical, time and personnel savings potential, and taking measures to protect against data misuse. This use allocates the responsibility of owners and operators of buildings in conserving resources and ensuring the economical, environmental and climate-friendly use, management and maintenance of a building (Technical and Building Facility Management).

However, little has been done to move forward and increase understanding of the ethical principles in corporate construction engineering environments to face the challenges of digitization and Al sustainably. The following Case studies, based on interviews with leading companies, serve to illustrate problems, opportunities and corporate engagement in applying digitization and Al. The more experts could be interviewed, the more sensitive analysis of the influencing factors could be analysed and experiences from practise in-depth could be discerned. That way, a more accurate responsible handling of digitization and Al could be described. Each company bears responsibility for educational knowledge, designing a structure and providing the requirements for participating in the digital transformation process. Within such context, this form of corporate responsibility is referred to as CDR in this study.

Bauer demonstrates the building-specific contextual relationships between science and practice [32]: "Due to the competition focussing on the price, the building industry is forced to maintain a high level of innovation through many special proposals. Digitization plays a significant role.... The many interfaces with other parties involved in construction make the construction process particularly time-consuming because of the many coordination requirements for digitization....." There are security problems with the fact that the data containing specific know-how of the data producer must be freely exchanged and used between those involved in the construction. Contracting parties must clearly regulate that the data always belong to the person who creates it and are only allowed to be used by others for a specific construction project. Planning services and, thus, BIM models are subject to copyright; the general data protection regulation (GDPR) also protects personal data.

Data always allow conclusions to be drawn about the people involved, such as the equipment driver and the work group. Bauer, therefore, suggests the precise definition of "which data are used for quality assurance and which are only used to put people under control." Experience in construction practice, so the common tenor of the interview partners demonstrate, that the greatest difficulty lies in complying with data regulations. That is why there is a need for specifically developed regulations. The handling of digital methods in construction, in particular the ethical principles, must be examined further. The author's survey of representatives of the Bavarian Construction Industry Association reveals that legal requirements by the state are absolutely necessary for safe and secure handling of data. The handling and protection of data in the age of digitization must be legally regulated [33].

A fundamental part of the study's CDR concept consists in creating awareness, in educating people about what digitization and $\mathrm{Al}$ can do, in analysing where chances and potential and also the risks lie, and how to deal with digitization and Al responsibly [34]. The best way to succeed is "taking people with you", making Al explainable and building trust. The centre of the ethical orientation of corporate action originates from three questions, first about the "highest good", second about the correct action in given situation and third about the freedom of will. Confidence in technology is achieved only through the ethical consideration of the use of a technical method, understanding of the functions, understanding the structure, transparency, but also communicating dangers and risks with regulated control mechanisms and reliable design. As soon as people understand, that they have control over digital application, their awareness of their self-responsibility in setting the digital course increases. Such a corporate culture is a fertile breeding ground for value-oriented, trustful and more efficient processes. To do justices to their significant influence, construction companies have a moral responsibility of self-commitment, supporting the individual processes in favour of the purpose of common good [35]. CDR increases innovation and growth in companies and strengthens the shared added value both for companies and society [36]. The study identified key elements for responsible digital transformation: clearly defining requirements (data, processes, qualification), quality features and interfaces, ensuring the consistent digitization of all planning and execution-relevant information data, and providing the consistent data platform that is used in all process phases by all participants. CDR goes far beyond compliance with legal norms [37]. When dealing with data or using Al systems, a company bears forward thinking social responsibility. Corporate responsibility implies creating one of the most important basic requirements: the partnership-based cooperation of all those involved in the construction project [38]. Most research institutes for ethics in Al perform interdisciplinary investigations by forming a working group with multidisciplinary representatives. Specialist knowledge enables holistic analysis and evaluation, e.g. in the automotive industry, medicine, biomedicine, law or the care sector.

The trend of the twenty-first century of growth with disproportionately high demand for new digital technologies 
and methods of Al not only signals the ethical impact of Al on society as a whole, but its call for a rapid shift from experimental to applied technology, adaptation to new organizational capabilities and establishment of internal governance. The increasing need to deal with Al changes the competitive landscape and encourages the search for improved methods to preserve the societal and human good [39]. This study complements previous work but is targeted at technologies that are new and will have a severe impact on people, society and diverse environments in the immediate future. The study identified best practice companies as Case studies, concluding that a culture of knowledge is the key resource to get engaged in the digital transformation.

The previous understanding required the specialist with special knowledge. Research findings show that today's experts in their field must have interdisciplinary knowledge ensuring holistic research. The study defines the engineering part as the integral part of professional and holistic examination. Interviewees highlight that ethical reflection in Al needs to be integral part of academic education. Thus, engineers will be able to weigh values and interests in their daily work as well as run an assessment of potential consequences. The engineer of tomorrow must have interdisciplinary knowledge and technical, social and personal skills to meet the challenges of his new fields of application, which make digitization and Al necessary. The discussion about human-led technologies includes the engineer of tomorrow's preparation to cope with valuebased decision-making processes and possess adequate skills. This field requires further in-depth research and long-term academic adjustments. The Institute of Ethics and $\mathrm{Al}$ at Oxford University in England is one best practice teaching "Ethics in Al for engineers" with the aim of teaching ethics as part of the engineering profile ("teach ethics as a skill"). Engineers are given the tools for ethically responsible use of $\mathrm{Al}$ in training via developing ethical awareness and the willingness to make ethical considerations part of daily decision-making processes.

During interviews and discussions in construction, ignorance, rejection, reservations about scientific interface work, a lack of foresight-often in management positions - were noted. One result of the study is that these imbalances have to be stated precisely, because they interfere with the exchange between specialist disciplines and the search for holistic solutions in the design of the digital transformation process, particularly the innovative progress in Germany. "In the technical sciences it is still a long way off, that values and principles are used and that ethics training has to be anchored in training." [40]. This study observes critically that progress and reform depend on dialogue and a new quality of discussion. Ethical values and codes of conduct must be further developed to strengthen trust in and promote new technologies, to use them sensibly and to provide orientation [41, 42].

After 2 years of work, the German Bundestag study commission provided recommendations for action for human-centred Al. In Baden-Württemberg "Cyber Valley Stuttgart-Tubingen" and "Al Innovation Park Baden-Württemberg" aim mapping globally competitive research and high-tech locations-similar to Silicon Valley. The study notes that there are initiatives approaching "ethics in Al" on the German level (including the German Ethics Commission "DEK"), the European and the international level (including SDGs, Roman Catholic Church). They inspire considerations in the construction industry. Successful companies that anchor an ethical strategy and a vivid corporate culture and mentality - this is proven by the expert interviews-possess an awareness of the added value potential resulting of applying digitization and Al methods and its employees' identification across the company.

For most construction companies, there is still a high need explaining digitization and $\mathrm{Al}$ and to be able to allocate where the use of Al makes sense and to identify its benefits. Experts share their Case studies and experiences applying Al and, thus, contribute to an eye-opening effect showing trust and transparency among users. Digital change requires trust, competence and value-based corporate culture according to "Trusted Human-Centered Engineering" [43]. More than ever, technology is the key to a new era of European culture of innovation. Corporate activity, social and ethical responsibility and environmentally conscious technological innovations merge. The sustainable, value-based design of the living and urban worlds of tomorrow with sustainable urban infrastructures is only made possible by ethical principles in dealing with digital technologies and AI.

The construction industry holds significant potential to create value in the digital transformation process. Merging new Al methods with existing digital models may lead to new working environments with eye catching concepts of Al (Table 3):

Ideally, digital transformation assists architects, planners and the operational part of construction, makes the interaction between workers and machines more efficient, performs partially automated processes and uses existing data to provide new experiences, its values and the basis for strategic decisions (= Self-learning construction site).

Experts conclude that machine learning has an estimated potential of value creation of $\$ 5.8$ trillion. This means that artificial intelligence has greater potential than the steam engine [44]. As one key outcome, the study identified precise indicators being advantageous for integrating $\mathrm{Al}$ and its use in the construction industry (Table 4).

Simultaneously, companies learn more about "undesirable side effects" initiated by digitization and how 
corporate responsibility has to change accordingly, in a continuous process. A key question emerges: how can successful companies develop their own individual strategy of digital responsibility using management tools to implement their strategy in dynamic markets and social environment? Some of the best practice companies share their experiences: "Such dynamics go hand in hand with corporate responsibility and embedding ethical value management in a society that is increasingly fundamentally changing from digitization and artificial intelligence technologies," said Schäfer [45], working for a German Association for certifying value-based corporate management concepts. "We are in the middle of a renaissance of value orientation", emphasizes Wieland; "moral values need to be implemented and routinized" [46]. A long-term Head of Civil Engineering faculty sees the education of values and ethics as an integral part of the engineer's academic training, because the course for the success of construction projects is already set there-by well-trained engineers who are prepared for digital transformation.

Companies increasingly search for ways to include ethical moral aspects into technical development and application from the very beginning and act according to their corporate responsibility based on the precautionary principle. Some discover ethical frameworks as enabler of new ways of thinking and acting: efficient orientation and support for managers and specialists in becoming more agile, acting more collaboratively, and focusing on new goals and business models.

Peter Mendler knows how to create trust, openness and fairness, because ethically justifiable products are more competitive. They are usually better received by the customer. Success and acceptance can only be achieved in projects such as the construction of the Al innovation park if, in particular, the ethical aspects are of essential importance. These dimensions are taken into account and integrated [47].

Thomas Gebhardt's core task is the transfer between teaching, research and application [48]. For him, the entrepreneurial responsibility in the digital transformation consists particularly in rethinking process and communication improvements in order to remain competitive. Craftsmen generally have a high level of ethics, values and demands for appreciation. The digital transformation consulting shows that raising awareness, education and knowledge transfer and exchange require communication in an appropriate language. Responsible, value-based corporate management in the craft requires strategic further development and no longer only to drive in the short term. Digitization/Al mean philosophy of construction and are more than a software product. In order to efficiently train algorithms, you need significant amounts of data. Cooperation is required instead of isolated solutions, and more networking. Ethics and framework conditions for digitization in construction are still a long way off. Thus, this pioneering study deserves full nationwide support and sends a very positive signal to the construction industry [49].

\subsection{Case study I: PERI digital transformation and corporate development [50]}

Company PERI is working on various potential fields of application of $\mathrm{Al}$ (object identification and automation of engineering tasks) based on a wide variety of methodological and technological approaches. Successful digital transformation at PERI means 'taking people with you', getting excited about $\mathrm{Al}$, with methods that solve a problem. The most suitable Al solution must support people by raising awareness, education and transparency. People are human capital; you don't want to keep people occupied if the same task could be solved faster and more efficiently by a machine. The integration of value chains-across companies-is the critical path to the success of digitization in the construction industry. What is important is a sensible use of $\mathrm{Al}$, geared towards the common good. We have anchored a large part of the "ethical" aspects in our management principles, significantly shaping our corporate culture.

\subsubsection{What risks and problems do you see in the use of digitization and Al?}

In order to develop meaningful Al techniques, the problem and the field of application must be defined first. The main question is: at what point does it make sense to address a problem? The network is missing to spread this question among the actors; this is a big weak point. There is a high need for education of Al due to the lack of knowledge about the possible uses of digital technologies and Al, which makes balanced, well-thought-out decisionmaking paths ethically highly questionable. Many people cannot define Al due to the-often incorrect-use of the term in the media and in discussions. Ethics and misuse are closely related, it is part of the corporate commitment to deal with and to look for value-based solutions. The aim remains problem solving for the benefit of the community, especially in the case of resource bottlenecks, at high costs!

\subsection{Case study II: Wayss \& Freytag digital construction (Royal BAM Group, NL) [51]}

"Digital Construction", a business unit of Wayss \& Freytag founded in 2016, copes with the challenge, that digital transformation and entrepreneurial culture form a cross-cutting issue. The associated change management is embedded in the daily work, and contributes to the 
Table 3 Key elements of Al in construction in its early phase of research and first technologies implemented. Source: Bianca Weber-Lewerenz

Digitization tools beyond BIM, e.g. helmets with Webcams, digital markers, digital online site visits with Virtual Reality Glasses, Simulation of Renovation concepts + Construction during use of building, Simulation Acoustics and Fire protection concept, Al Sensors to detect defects and damages, Sensors of material failures, changes of temperatures, humidity, Al Monitoring + Controlling according to construction progress)

Mixed Reality (MR)-Glasses, Hololens Glasses, Augmented Reality (AR) (Measurements of building elements/sections by creating digital twins)

Networking of all digital devices for complex data collection from all technical trades

Al-based accurate mapping of consumption and billing, Al-based Remote monitoring functions

Forecast and strategy data systems as an entrepreneurial basis for decision-making (predictive technologies)

3D-7D twin systems used for simulation, reality and forecasting models

Robots for automatic 3D-scans onsite

Self-conducting construction machines, autonomous and semi-autonomous bulldozers

Al data evaluation/derivation of recommendations/data use for training machine learning

The use of machine learning, deep learning, and social computing

Automatic analysis of building sections

Show the failure risks of construction machinery in real time using machine learning

Systems for structuring data complexity

Al-based identification of similarities to existing construction project data and use for new construction project data: for highest efficiency in resources, climate-friendly, cost and time

Smart technology and smart buildings, and

Self-learning construction sites

Table 4 Indicators to the benefit of integrating $\mathrm{Al}$ in the construction industry. Source: Bianca Weber-Lewerenz

\author{
Minimizing errors where people fail, \\ Structured data complexity, \\ Routine and standardized processes carried out by the machine, \\ More efficient time management: giving people more time for the processes that no machine is able to \\ perform (those that require creativity, human morality e.g.), \\ Knowledge networking across all digital borders, \\ Cost-efficient, sustainable and responsible resource-saving construction, \\ Increasing stability through "lean" building processes (Gehbauer 2006), \\ A tool for monitoring and fulfilling climate goals, \\ A tool for implementing the sustainable development goals given by the UN (SDGs), \\ High social contribution to the change towards a climate-friendly society, and \\ Increasing the share in the value chain
}

acceptance and enthusiasm of everyone working in the company.

The construction industry has traditionally been conservative. Structural problems exist with contracts, fragmented value chains, there is no networking and the influence of certain actors is missing. However, in order to develop useful Al techniques, the main question is: at what point does it make sense to address a problem? I also see risks and problems in the need for development of (a) consistency of the digital process, (b) data management on the construction site: previously administration took too much time, (c) data security, data protection: close company-internal exchange with appropriate experts (legal components are covered by our legal department in the company), (d) biggest hurdles for Al: data sources, data availability, big data far away, further use and use of the data, localization open.

Overall, I rate the existing lack of knowledge about the possible applications and the need for education about digitization and $\mathrm{Al}$ as very high. $\mathrm{Al}$ is supposed to help solve people's problems. Ethics means a guideline; for us, this is the focus for ensuring efficiency, best quality and safety.

\subsubsection{How important is ethics in the age of digitization?}

It is very high and one of the Wayss \& Freytag's guiding principles is the company's Code of Ethics and Code of Conduct. We do not have an additional code of ethics or ethics guidelines specially tailored to digitization and Al. 
It is part of the corporate commitment to deal with valuebased solutions. A problem solution for the benefit of the community! Common good makes the guideline! Value chains have to be integrated more and more.

\subsubsection{Is it important to regulate the ethical framework by law?}

Legal rules are important as a supporting function. The most important thing remains the appeal to corporate responsibility and a trustful cooperation between all those involved in construction. No additional legal regulations are required; these are more of a hindrance to innovation. We see this in Germany, as part of the BAM Group, compared to UK and the NL.

\subsection{Case study III: APLEONA [52]}

In practice, there are barriers to adapting digital/AI solutions. The reason for this is, among other things, are the specification-based contract models between Facility Management companies and their customers, which are still common in Germany. The need for clarification at this point is high.

For Apleona, digital transformation means a win-win-win partnership between our customers, us and our subcontractors. In addition, we see the opportunity through digital solutions to expand our service portfolio (always primarily based on the business case: solving a customer problem in an economically efficient way (fast amortization phase, high energy savings).

\subsubsection{Where do ethics play a role?}

It's always about problem solving. The starting point for every consideration of a digital solution: focus on people, design thinking for the "use case": here the user is the key factor.

\subsubsection{What are the difficulties in FM when dealing with data?}

Dealing with the customer's data is a challenge. Here, the general data protection regulation provides the framework. The principle is that the data generated by the customer also belongs to the customer.

The Al methods that we are working on and with which we are already partially using are self-learning technologies in energy and $\mathrm{CO}^{2}$ optimization. We are aiming for a "fully automated building technology control" (Predictive Control, already implemented). On average, about $20 \%$ energy savings can be achieved with relatively little effort. The reality shows, however, that in some cases, building owners do not want to give building control out of their hands; in addition, successful implementation requires an initial effort, an investment that must be borne by one of the stakeholders. Ideally, that should also be the one who benefits from the savings. Technicians and engineers have to understand the potential and functionality of the digital solutions (user interface), but not necessarily the Al technology behind them.

In the application of digitization and $\mathrm{Al}$, a high priority is that the business case pays off. Investments are made when the investor is also the one who benefits from the investment-which is not a matter of course in building operations (example: building owner invests in building technology, tenant benefits from lower ancillary costs). Suitable incentive structures must be created. The situation is similar with other use cases of digitization/Al (e.g. $\mathrm{BIM}$ ). One solution would be that the legislature regulates by guidelines.

\subsection{Case study IV: Wood construction technology sector}

Al supports the manufacturing process of better, technically modified wood. Machine learning $(M L)$ is already being used in wood technology applications: Al supports the digital wood selection and wood processing strategy to obtain specific physical properties. Such technology helps to face ethical, environmental and legal concerns about deforestation and use of endangered tropical timber. By maintaining the craft of traditional musical instrument production, an important social and economic contribution can be made to increase the share in the value chain.

Deep learning supports a high-quality wood production. ML optimizes the functionalization of wood: material selection, physical data of the raw material, production steps, process parameter setting, quality control, processing, prediction of product quality in real time. Only through neural networks is it possible to sort the flood of data and data complexity (MLA machine learning algorithm).

This is central topic in the question of dismantling, reusability, recycling, ecological and energy conception in the context of the sustainability discussion.

These Case studies highlight the urgency of taking corporate responsible measures, and defining approaches and ethical principles to make full use of the potentials of digitization and Al. Companies consider themselves as actors, seize opportunities, weigh up risks and deal with them safely, reflect on values, design ethical standards and framework conditions [53], and make their contribution to the value chain. The practical guide CDR [54] on corporate 
responsibility and sustainability management in the digital age pays particular attention to Ethics.

In order to design state-of-the-art city systems, efficient city logistics, mobility and innovation systems fulfilling SDGs, the question arises in some interviews: who are the actors, the masterminds and designers, who are the executors? Local climate adaptation strategies, digital strategies, the living and urban worlds of tomorrow, sustainable urban infrastructures, sustainable design of space and society can only be achieved with the help of experts and know-how.

\subsection{Discussion of the case studies and outlook of the work}

This study comes to the conclusion that standards that both promote the efficiency of human work and comply with SDGs should be established. Not only developers of Al but users and political and societal decision-makers among the interviewees support standards by law. Al structures and evaluates data complexity and prepares it for human use in a clear manner that affects all industries, enabling minimization or prevention of human errors, continuous access and maximum transparency. Ethically, moral decision-making processes can be supported by Al and thus help people during the process. Protection of natural resources can be ensured by using Al-supported calculation, analyses and forecasts (e.g. material savings, logistics efficiency). Climate protection can be strengthened through forecasts and recommendations for action developed by Al. Al data evaluations facilitate corporate strategy development. Al increases human work efficiency: if routine and standardized processes are carried out by Al, humans can spend more time concentrating on creative work processes which cannot be transferred to machine or artificial intelligence. Since $\mathrm{Al}$ is trained and managed by humans with the aim of providing the most humanfriendly and economically efficient support, humans determine the areas in which Al should be applied. People control Al, not vice versa. Such knowledge builds trust, relieves fears, and provides clarification. Al builds up and maintains security and safety where human failure and error may occur. The ethical strategy in $\mathrm{Al}$ in construction could be designed as follows:

Goals:

- to meet the sustainability goals,

- to make Germany and Europe the leading location for the development and application of value-based $\mathrm{Al}$ technologies

- to promote culture of awareness and alignment of $\mathrm{Al}$ with ethical values, supported by the associated legal regulations.
Standards:

- to ensure the common good-oriented development and use of $\mathrm{Al}$,

- to secure the competitiveness of the construction industry in Germany,

- to embed Al ethically, legally, culturally and institutionally in society as part of a broad social dialogue and active policy making,

- to support education and awareness-raising for the potentials, opportunities and risks of Al,

- to set up a concept relating to the ethical standards in Al (Common European Path) that applies to all European member states.

A consensus emerged in the Case studies, companies and institutions examined in this study: responsible innovation and ethics remain as challenging as before and undoubtedly even more difficult in increasing complex environments and new, rapidly developing datadriven technologies such as Al [25]. Human-machine interaction represents a partnership that distinguishes between human and artificial intelligence. It is a commitment to a balanced technology. Some corporate and stakeholder interests may not be in line with legal standards. The interviewees agree that the functions of Al shall be transparent and its application safe, so it can support human work sensibly and enhance the economic efficiency while maintaining the safety and security of the data and contributing value to the common goodfar beyond financial interests only. But there is no consensus on whether the self-commitment is going to be sufficient in the long run or if standards by law need to be binding for each company and institution. There is a huge gap between how to mitigate such a risk of greenwashing and how binding standards should look like. The status quo is dominated by recommendations and general principles that are guiding rather than binding.

It makes a big difference whether a company cultivates and upholds a culture of values, compares its technological progress with safe, meaningful and responsible human-machine interaction, or if it only relies on PR campaigns that encourage particularly ethical, fair action by the entire company or strategies put in a "green" light (greenwashing).

On the other hand, legal requirements can force a company into pointless documentation efforts, which make processes inefficient, and delay technical developments and progress. When examining who can best fill out the supervisory authority for compliance with ethical standards, the majority of those questioned in this study appealed to self-responsibility but also called for an independent supervisory authority. For reasons 
of data protection in particular, the surveyed experts demand uniform regulations from the legislature.

Grunwald advises to debate the economic efficiency hand in hand with ethical issues [55]. Society sets the values, people shape society. Businesses can be forced to fulfil ethical responsibilities by their customers, the users. That means corporate standards need to be enforced-it's a kind of awareness and informative level, a very proactive way. Ethics should accompany the process of Al development and decision-making from the beginning.

Kiefer, Consultant for international occupational policy and technical education at the Association for German Engineers VDI [56] starts with the integration of ethics in engineering training and teaching. The sensible use of new technologies .... requires ethical principles right from the very start. The engineer requires a holistic, moral, value-based, interdisciplinary approach. Digital transformation changes the engineer's profile, qualifications and competencies. Responsibility and ethical behaviour require adjustments in the academic education and teaching. In times of digitization and $\mathrm{Al}$, ethics and interdisciplinary cooperation are mutually dependent as education and awareness-raising are the linchpin for explainability, transparency and trust in the new technologies. Compared to Germany, e.g. the separate consideration of "technology ethics" and "engineering ethics" does not exist in all countries.

Some interviewees highlight the role model function of institutions and companies-particularly in politics, academic teaching, research and science, but also the professional chambers and professional associations. They are multipliers for the ethical discussion about digitization technologies in construction and regulate compliance with ethical principles in a binding manner. The specification of the European regulatory framework for $\mathrm{Al}$ should be part of binding European legislation, not least to make the European data strategy the most secure in the world. It is a corporate responsibility to train knowledge and provide the infrastructure for fulfilling requirements for shaping digital transformation and anchor values in the corporate culture as to bridge the gap between Ethics and practice for trustworthy Al technologies. Some of the large companies engage ethical experts, so-called "Ethics Boards". The presence of a CDO (Chief Digital Officer) or $\mathrm{CIO}$ (Chief Information Officer) is often an indicator of the structural change as part of corporate digital transformation. Such personnel infrastructure modifications and tailored departments are only affordable due to the financial background of large companies, required to demonstrate ethically correct behaviour to investors and stakeholders. Another reason is the in-house research and development (R\&D) carried out by large companies in order to successfully master existing and future challenges - up to and including the technological role model for competitors.
SMEs often do not have such strong financial backgrounds; they face market competition and can only survive by offering niche products or low-cost services. Confronted with economic bottlenecks, the majority is busy with surviving the day-to-day business. Most SMEs are not involved in research collaborations, nor do they develop technologies themselves. The study revealed a high level of dissatisfaction with the in-house digitization.

Companies experience increasing complexity and quantity of data. Disregarding their size they have to adopt uniform data platforms, accessible to all parties involved, to have data available at all times, in the updated version and in its entirety, without any data loss. Most construction companies do not want to miss out on being part of digital transformation, but rather want to conduct efficient business, reduce costs, remain and increase competitiveness, increase customers' confidence and generate new orders. One of the key factors, the study identified, is stability and sustainability by setting up safe digital transformation environment to handle corporate data securely and protect against misuse.

It is not far-fetched to conclude that the communication language required for digital transfer also needs to be different and less technical, because not everyone is an $\mathrm{Al}$ expert or has access to this specialist knowledge.

Interviewees stress that large companies and SMEs have in common, that they possess the potential to build up knowledge and skills, to contribute to reducing $\mathrm{CO}^{2}$, to do their work in a more resource- and time-efficient manner, also for the benefit of society. Because services that are based on comprehensible ethical standards tend to be more successful in the market, 49 per cent of companies consider their services most competitively when in compliance with ethical standards [57]. This means that ethical standards are rated as more important than functionality. The pressure from consumers' expectations for compliance with ethical standards is increasing.

Both large companies and SMEs want to achieve success and add value, but the majority neither knows or searches for ways or their own digitization strategy to achieve this goal, nor recognizes or searches for advantages and potential fields of application.

Some countries are pushing digital innovation forward via government funding. Many interviewed political decision-makers state that companies still benefit from the success of past years, and plan "on sight". They feel no need for switching to digitization, start innovative paths or change business models. They consider Al as something far away. Interviewees from large corporate entities, representing best practices and adapting to innovative strategies and new technologies, confirm this attitude in many companies and estimate their competitiveness as very low and their chances at survival as slim. However, precisely 
these companies exclude themselves from digital project contracts because they are not compatible with customer's digital project infrastructures. A new company cell phone and construction plans or time schedules on paper do not go together. Being unable to answer tenders digitally is a rejection criterion, as it demonstrates a company's inefficient project process, without digital networking. Having to search for information in the office first and not offering a uniform data platform to employees is no longer up to date. Regardless of the size of the company, clients trust in and award companies for new projects that are up-to-date and deal with the invested budget responsibly, transparently and with high-quality performance. The same applies to selection criterion for graduates and highly qualified workers for choosing a company and applying for jobs.

There is a gap between desire and reality: many construction companies and suppliers are just spectators of new technology trends, instead of co-designers. Scepticism can only be countered with knowledge. The cooperation between industry and SMEs with technology startups and the formation of regional networks and clusters is seen as the most important solution, because it has developed positively in recent years. Start-ups are particularly suitable cooperation partners for SMEs that localize the options for using Al and introduce and train the appropriate technological solution for the company. The German Federal Association for Al (German KI Bundesverband e.V.) is committed to ensuring to use this technology in best sense of European and democratic values and to achieve European digital sovereignty.

For all companies, the key to success is building up knowledge about digitization and $\mathrm{Al}$ and using it responsibly. Times of crisis prove once again that the digitally wellpositioned companies are better positioned, and they are flexible to act and able to continue their work.

The US National Institute of Standards and Technology, the Defence Innovation Board and the National Security Commission on Artificial Intelligence joined the public discourse and released their own recommendations for ethical Al use. Such acting and setting guidelines on a highly official level send a strong signal and underline the importance of this study.

That said, this study invites leaders and users of digitization and $\mathrm{Al}$ to take responsibility to shape the ethical framework for $\mathrm{Al}$ and to participate in international debates, e.g. EU-uniform concept for ethically justifiable Al, European Ethic Guidelines for trustworthy Al, European Data Strategy, Digital Europe and Digital Technologies Initiatives, European Green Deal, SDGs by the United Nations, Rome Call for Ethics and the centre for development and progress of Al, funded by German Ministry of Economic Affairs.

\subsection{Limitations}

CDR is limited. What use are openness and basic technical equipment if general and specialist knowledge are missing? Here, the focus is on the educational landscape, which must enable targeted training in specialist knowledge about Al. The shared experiences of the respondents show that companies urgently need qualified staff in order to introduce new digital technologies into the company and to determine its ethical framework.

But the process of understanding that is recognizing the advantages, potential, opportunities and risks and to know to whom to address questions lacks adequate language transfer between science and construction industry. One of the key factors of building trust and understanding the sense of using these new technologies lies in its explainability towards companies and potential users. Another key factor is that the construction branch benefits from past years' orders. It is a critical path that the construction industry still follows traditional ways as long as there is no pressure for change such as regulations of the law. The Construction industry consists mostly of SMEs. Large companies might represent the minority but are functioning as role models in starting researching and applying Al. The ethical understanding as part of their CDR urges them to share their findings and exchange knowledge with SMEs. In Germany, however, some parts of construction industry lack awareness and willingness to adopt new perspectives and to consider approaches from other disciplines. They are not recognizing the advantage of taking up social, explicitly ethical approaches in the field of engineering and building technology. At the same time, this attitude prevents economic growth, data safety and gains from active prosperous participation in the digital transformation process. This is even more critical since every company is required to deal with increasing technical challenges combined with new digital technologies in changing global markets. In order to accelerate the technical digital progress, a radical rethinking-far from deep-rooted ways of thinking - and further research is required. Funds that have not been used up to now reflect this untapped potential. Overcoming such limitations, Germany can set a milestone to be an international location of research and education and increase significantly its share in the value chain. In principal, the interviewees agree that Al should be used where it makes sense, supports people, ensures safety of human work, and increases the efficiency of work processes. The ethical framework helps to overcome the existing limitations mentioned by this study, and it gives meaning to human beings and human actions alike and, thus, represents the key of the highest human performance. 
An additional limitation is represented by academic teaching that has not been adjusted in terms of academic teaching staff's skills and competencies to train and prepare students for ethics and digital transformation processes and its requirements. Companies are not able to fill positions with qualified engineers and experts having completed their academic education as they neither are nor prepared for ethically balanced decision-makings on a daily basis, nor for applying digital technologies and $\mathrm{Al}$ methods.

The study's research moves the Body of Knowledge forward by providing constructive solutions, a framework and an inclusive approach to fill these gaps and to shape digital transformation with focus on the specific needs of supporting the construction industry at all levels.

\section{Conclusions}

The study found that the CDR concept in the construction industry, incorporating ethical principles, provides the critical foundation for the use of innovative digital and AI technologies. This project describes ways that enable the exploitation of existing potential.

By shaping the technological landscape, developing adequate skills and fully use the potential, companies can lead this process to success. Tackling this challenge is a top priority in construction. Nevertheless, there is a lack of recognizing fields of application and potential. Knowledge of digital technologies and methods must first be acquired comprehensively in order for companies to be able to assume digital responsibility for something that many do not yet know or cannot assess [58]. It is a prerequisite for the greatest possible social benefit, economic prosperity and protection of our natural foundations of life. It should be of such a design that companies can guarantee secure data management, as well as access and use of new technologies by everyone.

Fortunately, there is growing awareness among leading artificial intelligence researchers and developers that human-centred designs are needed [59]. The study comes to the conclusion that a sustainable digital transformation can only succeed and the shares in the value chain can only be increased if humans are placed at the centre of technological developments. So far missing ethical principles are seen as limitations of success. However, they offer people orientation and support in order to be able to design and use digitalization and $\mathrm{Al}$ in a targeted and meaningful way and to be able to make balanced decisions with increasing complexity of data and decisionmaking options.

The study's findings, Case studies with shared experiences with applied $\mathrm{Al}$ and new aspects support the journal's excellent interdisciplinary linkages. The study contributes to shape value-based, sustainable digitization and $\mathrm{Al}$ and raises awareness of the responsible role of the construction industry.

The results and limitations presented in the study show that successful companies have recognized the advantages of ethical principles and have embraced them in order to use new innovative technologies for themselves with determination. What is lacking are the required technical and personal qualifications of tomorrow's engineers, an adapted way of academic teaching, the interdisciplinary dialogue, courage and the will to innovate, although these factors represent the key competencies for a competitive construction industry.

This study can be used for the validation of follow-up studies in order to check developments in the humantechnology relationship and to introduce recommendations for any necessary corrections into the scientific discourse. This supports the further development of technology ethics with advancing technology and increasing challenges for people.

A field of tension in the educational landscape is seen in the balancing act between training basic engineering skills and additional new technical competencies. On the other hand, universities use their strategies of excellence to differentiate themselves from the competition with targeted clusters of research, innovation and interfaces.

Similar impressions arise in large companies, active around the globe, that are enhancing their appeal as employers, but also want to meet their social responsibility. So far unused funds that are available for Al research and application show that too few are still taking on the challenge.

The study results show that it is time for a radical rethinking process, especially in SMEs: taking responsibility, breaking boundaries, leading. Engineers, architects, designers and craftsmen are not only designers of living environments, but also of technical, social and human change in the Construction Industry 4.0. The research makes several useful recommendations for the Construction industry not only fulfilling technical regulations, but implementing human-tech guidelines.

It is also the only study suggesting to making an example of the construction industry by using Al sensibly, reliably and responsibly. A study raising public debate with focus on the construction industry about "A transparent and ethical Al-Made in Germany", understood as a quality label, not only following a national strategy, but rather a European one in order to strengthen sustainability and growing into the role of a prosperous and strong global partner. Therefore, further in-depth research on an interdisciplinary basis is needed. To understand what Al, its function, its chances and risks are about, how certain 
methods may enable improved or new business models, what measures and which responsibilities must be taken responsibly, the communication language between research-education-practice needs adjustments.

The study sends a strong signal on how important it is that the construction industry gets engaged now-not only to strengthen its own competitive role and highlight its unique selling point, but also to not to be left behind in the era of digital transformation. Best practices increase attention for integrating considerations of ethics and values into the development of digital technologies and $\mathrm{Al}$ $[60,61]$. There is a strong need for responsible innovation by inclusion for currently emerging data-driven technologies to rethink how these shall be conceptualized, introduced, and implemented [62]. This concept and framework of CDR offer not immediate beneficiaries but rather long-term benefits and orientation for humans, society and technology with strong sustainability over the next decades. This lays the foundation for Al and digital technologies helping humanity prosper. This study is especially targeted at understanding the critical path and key processes of the digital transformation in the construction industry. The findings define CDR's opportunities and risks to deliver significant improvements on corporate business models using Al safely and for the benefit of both corporations and the common good. The study identified CDR with ethical principles as the key driver for success, resources-cost-time efficiency and sustainability using digital technologies and $\mathrm{Al}$ in construction engineering.

The study suggests the intrinsic value of a successful innovation culture that can be allocated and shown in annual group reports ("Combined financial and sustainability report") transparently as an independent item, as well as the human factor contributing to reducing costs. This could increase the trust of stakeholders, entrepreneurial identification and appeal in terms of external impact.

\begin{abstract}
Acknowledgements I would like to thank all contributors and interviewed experts for their valuable support for this study. Numerous institutions, initiatives and associations support this inclusive holistic research on $\mathrm{Al}$ contributing engineering and philosophy expertise leading to the foundation of the Excellence Initiative for sustainable, human-led Al in Construction as part of a larger global network. For the great cooperation throughout my scientific research I thank Fraunhofer Institute IAO for joining forces to embed the ethics debate as the driver of success for digital innovation and digital economy.
\end{abstract}

Author contributions I am the single author contributing to the study conception and design. Material preparation, data collection and analysis were performed by me, Bianca Weber-Lewerenz. I read and approved the final manuscript. The author confirms the following statement: All data, models, and code generated or used during the study are part of the submitted article. This includes all data provided by third parties. All interview citations and interview sources have been confirmed for publication by the interviewees.

\section{Declarations}

Conflict of interest The author(s) declare that they have no competing interests.

Ethical standards Publication permission was given by all respondents. Some public statements, which come from internet, literature and archive research, also underline the quality and statistical values of the expertise and survey values obtained, as well as limitations and urgently necessary measures. The author of this study conducts external research, is company-independent and is not financially supported by third-party funds, companies or other institutions. She is free in her research and shares her findings at the interface of "application practice-applied technical research-economic and social transfer". In this way, the author is researching the responsible use of digitization and $\mathrm{Al}$-neutrally, critically and inclusive-and promoting the ethical debate about the Al technologies.

Open Access This article is licensed under a Creative Commons Attribution 4.0 International License, which permits use, sharing, adaptation, distribution and reproduction in any medium or format, as long as you give appropriate credit to the original author(s) and the source, provide a link to the Creative Commons licence, and indicate if changes were made. The images or other third party material in this article are included in the article's Creative Commons licence, unless indicated otherwise in a credit line to the material. If material is not included in the article's Creative Commons licence and your intended use is not permitted by statutory regulation or exceeds the permitted use, you will need to obtain permission directly from the copyright holder. To view a copy of this licence, visit http://creativecommons. org/licenses/by/4.0/.

\section{References}

1. Di Vaio A, Palladino R, Hassan R, Escobar O (2020) Artificial intelligence and business models in the sustainable development goals perspective: a systematic literature review. J Bus Res 121:283-314

2. Di Vaio A, Palladino R, Pezzi A, Kalisz DE (2021) The role of digital innovation in knowledge management systems: a systematic literature review. J Bus Res 123:220-231

3. Grunwald A (2009) Zum Handlungsbegriff in Technikphilosophie und Technikethik (The terms of technical philosophy and technical ethics), No. 2. (in German). https://www.widerstreitsach unterricht.de Accessed 25 Feb 2020

4. Aristotle (2009) Nikomachische Ethik (Nicomachean ethics). (in German). Translated by Eugen Rolfes. Anaconda Publishing, Cologne

5. Kant I (1781) Kritik der reinen Vernunft, 1781/1787 (Critique of pure reason). (in German). Translated by Norman Kemp Smith (1965). New York, Toronto

6. The Pontifical Academy for Life in Rom (2020) Rome call for Al ethics guideline, 1st edn. The Pontifical Academy for Life in Rom, Rome

7. United Nations (2016) The 17 SDGs. https://sdgs.un.org/goals. Accessed 25 Feb 2020

8. European Commission (2020) White paper on artificial intelligence-a European approach to excellence and trust, 1st edn. European Commission, Brussels

9. Data Ethic Commission of German Government (2019) Assessment on data ethic. Universitätsdruckerei und Verlagsgesellschaft Potsdam mbH (bud), Berlin 
10. White House Office of Science and Technology Policy (OSTP) (2019) Executive order no. 13.859, maintaining American leadership in artificial intelligence, 84 Fed. Reg. 3967. https://www. whitehouse.gov/presidential-actions/executive-order-maint aining-american-leadership-artificial-intelligence/. Accessed 28 July 2020

11. Vossenkuhl W (2006) Die Möglichkeit des Guten-Ethik im 21. Jahrhundert (Possibility of the good-ethics in the 21 st century), 1st edn. C. H. Beck oHG Publishing Company, Munich (in German)

12. Spiekermann S (2019) Digital ethics: a value-based system for the 21 st century, 3rd edn. Publishing Company Droemer HC, Munich

13. Nida-Rümelin J, Weidenfeld N (2018) Digitaler Humanismus: Eine Ethik für das Zeitalter der Künstlichen Intelligenz (Digital humanism: an ethics for the age of $\mathrm{Al}$ ), 4th edn. Piper Verlag GmbH Publishing Company, Munich (in German)

14. Lenzen M (2019) Künstliche Intelligenz: Was sie kann \& was uns erwartet (Al: what it can do and what awaits us), 3rd edn. C. H. Beck Publishing Company, Munich (in German)

15. Zweig K (2019) Ein Algorithmus hat kein Taktgefühl: Wo künstliche Intelligenz sich irrt, warum uns das betrifft und was wir dagegen tun können (An algorithm has no tact. Where $\mathrm{Al}$ is wrong, why it affects us and what we can do about it), 1st edn. Heyne Publishing Company, Munich (in German)

16. Roller MR, Lavrakas PJ (2015) Applied qualitative research design: a total quality framework approach. Guilford Publications, New York City

17. Mayring P (2015) Qualitative content analysis: theoretical background and procedures. Approaches to qualitative research mathematics education. Springer Publishing, Dordrecht, pp 365-380

18. Creswell HW, Poth CN (2017) Qualitative inquiry and research design: choosing among five approaches, 4 th edn. SAGE Publications, Thousand Oaks

19. Giannakidis A, Weber-Lewerenz B, Stolze D (2021) Al in construction: possible applications for planning, realizing and operating buildings. Fraunhofer IAO Institute Publishing. https://www.ki-fortschrittszentrum.de/de/studien/ki-in-derbauwirtschaft.html Accessed 19 April 2021

20. Bryson JJ, Theodorou A (2019) How society can maintain human-centric artificial intelligence. In: Toivonen M, Saari E (eds) Human-centered digitalization and services. Translational systems sciences, vol 19. Springer, Singapore, pp 305323. https://doi.org/10.1007/978-981-13-7725-9_16

21. Baker-Brunnbauer J (2020) Management perspective of ethics in artificial intelligence. J Al Ethics. https://doi.org/10.1007/ s43681-020-00022-3

22. Deloitte (2021) 2021 engineering and construction industry outlook in the US. In: Study by Deloitte Research Center for Energy and Industrials 2021, p 2. Publishing Company Deloitte

23. Kiron $D$ et al (2013) The benefits of sustainability-driven innovation. MIT Sloan Manag Rev. https://doi.org/10.1002/97811 19204084.ch15

24. Schumacher EG et al (2013) Institutionalizing ethical innovation in organizations. An integrated causal model of moral innovation decision processes. J Bus Ethics. https://doi.org/ 10.1007/s10551-012-1277-7

25. Fisher $E$ (2020) Reinventing responsible innovation. Sci Technol Soc Stud J Responsib Innov 7(1):1-5. https://doi.org/10. 1080/23299460.2020.1712537

26. Pillai VS, Matus KJM (2020) Towards a responsible integration of artificial intelligence technology in the construction sector. J Sci Public Policy 47(5):689-704. https://doi.org/10.1093/ scipol/scaa073
27. Royakkers L, Timmer J, Kool L et al (2018) Societal and ethical issues of digitization. J Ethics Inform Technol 20:127-142. https://doi.org/10.1007/s10676-018-9452-x

28. Enquête-Commission of the German Bundestag (2020) Künstliche Intelligenz-Gesellschaftliche Verantwortung und wirtschaftliche, soziale und ökologische Potenziale. Abschlussbericht der Enquête-Kommission, Dokument No. 19/23800 (Al-social responsibility and economic, social and ecological potential. Final report. Document No. 19/23800), 1st edn. German Bundestag, Berlin. (in German)

29. Heidelberger M (2020) Künstliche Intelligenz managt Daten in der Bauwirtschaft-KIT Karlsruhe (AI manages data in construction industry-KIT Karlsruhe). Unternehmer Brief Bauwirtschaft 43(2):22-23 (in German)

30. German Federal Ministry of Transport and Digital Infrastructure BMVI (2017) Umsetzung des Stufenplans Digitales Planen und Bauen-Erster Fortschrittsbericht (Implementation of the step-by-step digital planning and construction-first report of progress). BMVI, Berlin (in German)

31. Sacks R et al (2010) Interaction of lean and building information modelling in construction. J Constr Eng Manag. https:// doi.org/10.1061/(ASCE)CO.1943-7862.0000203

32. Bauer T (2020) Digitization, Al and ethics in construction. In: Telephone interview with Bianca Weber-Lewerenz, 17 March 2020

33. Schmid T (2020) Digital transformation and ethics in construction. In: Interview with Bianca Weber-Lewerenz, 2 March 2020 in Munich

34. Smith B (2018) The future computed-artificial intelligence and its role in society. Microsoft Corporation Redmond, Washington

35. Scheffler M (2019) Moralische Verantwortung von Bauingenieuren. Problemstellungen, Perspektiven, Handlungsbedarf. (Moral responsibility of civil engineers. Problems, perspectives, need for action). Springer Publishing Company, Wiesbaden (in German)

36. Porter ME, Kramer MR (2012) Shared value: Die Brücke von Corporate Social Responsibility zu Corporate Strategy (Shared value: the bridge between corporate social responsibility to corporate strategy). In: Schneider A, Schmidpeter R (eds) Corporate social responsibility-Verantwortungsvolle Unternehmensführung in Theorie und Praxis (Corporate social responsibilityresponsible corporate management in theory and practise). Springer Gabler Publishing Company, Berlin (in German)

37. Koska C, Filipović A (2019) Corporate Digital Responsibility muss mehr als geltendes Recht abbilden (Corporate digital responsibility must reflect more than applicable law). (in German). https://www.future-of-hr.com/2019/10/corporate-digital-respo nsibility-muss-mehr-als-geltendes-recht-abbilden. Accessed 25 Feb 2020

38. Girmscheid G (2016) Projektabwicklung in der Bauwirtschaftprozessorientiert-Wege zur Win-Win-Situation für Auftraggeber und Auftragnehmer (Project management in construction industry-process oriented-win-win for client and contractors). Springer Publishing, Berlin (in German)

39. Xu W (2019) Towards human-centered Al: a perspective from human-computer interaction. Interact Mag. https://doi.org/10. $1145 / 3328485$

40. Loh J (2018) Künstliche Intelligenz und Ethik: Alles gut, oder was? (Al and ethics: All well?). (in German) panel discussion 5 December 2018. Telekom Headquarter Bonn, Germany. https:// youtu.be/W1v46rBQ3tc. Accessed 12 Dec 2020

41. Walsham G (1996) Ethical theory, codes of ethics and IS practise. Inf Syst J. https://doi.org/10.1046/j.1365-2575.1996.00105.x

42. Wright $D$ (2011) A framework for the ethical impact assessment of information technology. J Ethics Inform Technol. https://doi. org/10.1007/s10676-010-9242-6 
43. Shneiderman B (2020) Human-centered artificial intelligence: reliable, safe and trustworthy. Int J Hum Comput Interact 36(6):495-504. https://doi.org/10.1080/10447318.2020.17411 18

44. Bughin J, Seong J, Manyika J, Chui M, Joshi R (2018) Notes from the frontier: modelling impact of Al on the world economy. Study, Publishing Company McKinsey Global Institute (MGI)

45. Schäfer M (2020) Ethics in construction. In: Interview with Bianca Weber-Lewerenz, 10 February 2020 in Stuttgart

46. Wieland J (2014) Ethics. In: Interview Bosch global, March 2014. https://www.bosch.com/de/stories/josef-wieland. Accessed 25 Feb 2020

47. Mendler, $\mathrm{P}$ (2020) Ethics in digitization and Al in construction. In: Telephone interview with Bianca Weber-Lewerenz, 17 December 2020

48. Gebhardt, $\mathrm{T}$ (2020) Ethics in digitization and Al in construction. In: Telephone interview with Bianca Weber-Lewerenz, 16 December 2020

49. Hagemann-Miksits R (2020) Digital transformation and experiences with Al in construction. In: Interview with Bianca WeberLewerenz, 25 March 2020 in Berlin

50. Stadel D (2020) Digital transformation and experiences with AI in construction at Peri company. In: Telephone interview with Bianca Weber-Lewerenz, 4 November 2020

51. Krause D (2020) Digital transformation and experiences with $\mathrm{Al}$ in Construction at Wayss \& Freytag company. In: Telephone interview with Bianca Weber-Lewerenz, 4 November 2020

52. Lange $M$ (2020) Digital transformation and experiences with AI in construction at Apleona company. In: Telephone interview with Bianca Weber-Lewerenz, 5 November 2020

53. Altmeppen KD, Filipović A (2019) Corporate digital responsibility. Zur Verantwortung von Medienunternehmen in digitalen Zeiten. Commun Soc J. https://doi.org/10.5771/ 0010-3497-2019-2-202

54. Dörr S (2020) Praxisleitfaden CDR: Unternehmerische Verantwortung und Nachhaltigkeitsmanagement im Digitalzeitalter (Corporate responsibility and sustainability management in times of digitalization), 1st edn. Springer Gabler, Wiesbaden (in German)

55. Grunwald A (2020) Virtual AI roadshow USA-Baden-Württemberg-Canada. Panel discussion 18 November 2020. https:// virtual-ai-roadshow.b2match.io/. Accessed 18 Nov 2020

56. Kiefer T (2020) Digital transformation and experiences with Al in construction. In: Telephone interview with Bianca WeberLewerenz, 3 December 2020

57. Federal Association of the Digital Economy (2019) Ethik wird zum Wettbewerbsfaktor. (Ethics is becoming a competitive factor). Study on DMEXCO by German BVDW e.V. (in German). https://www.bvdw.org/der-bvdw/news/detail/artikel/ bvdw-studie-zur-dmexco-ethik-wird-zum-wettbewerbsfaktor. Accessed 6 Sept 2020

58. Shneiderman B (2020) Bridging the gap between ethics and practice: guidelines for reliable, safe and trustworthy humanentered Al systems. ACM Trans Interact Intell Syst Mag. https:// doi.org/10.1145/3419764

59. Jordan MI (2018) Artificial intelligence-the revolution hasn't happened yet. Medium.com. https://medium.com/@mijor dan3/artificial-intelligence-the-revolution-hasnt-happenedyet-5e1d5812e1e7. Accessed 12 May 2021

60. Hao K (2019) In 2020, let's stop Al ethics-washing and actually do something. MIT Technology Review. https://www.technology review.com/s/614992/ai-ethics-washing-time-to-act/. Accessed 12 May 2021

61. Teerlink M (2019) Ethics in Al: why values for data matter. Forbes. https://www.forbes.com/sites/sap/2019/12/18/ethics-in-ai/\# 5477c3d45af4. Accessed 12 May 2021

62. Valkenburg $\mathrm{G}$ et al (2019) Responsible innovation as empowering ways of knowing. J Responsib Innov. https://doi.org/10. 1080/23299460.2019.1647087

Publisher's Note Springer Nature remains neutral with regard to jurisdictional claims in published maps and institutional affiliations. 